\title{
Cochrane
}

Cochrane Database of Systematic Reviews

\section{Medical interventions for treating anthracycline-induced symptomatic and asymptomatic cardiotoxicity during and after treatment for childhood cancer (Review)}

Cheuk DKL, Sieswerda E, van Dalen EC, Postma A, Kremer LCM

Cheuk DKL, Sieswerda E, van Dalen EC, Postma A, Kremer LCM.

Medical interventions for treating anthracycline-induced symptomatic and asymptomatic cardiotoxicity during and after treatment for childhood cancer.

Cochrane Database of Systematic Reviews 2016, Issue 8. Art. No.: CD008011.

DOI: 10.1002/14651858.CD008011.pub3.

www.cochranelibrary.com

Medical interventions for treating anthracycline-induced symptomatic and asymptomatic cardiotoxicity during and after treatment for childhood cancer (Review) 
TABLE OF CONTENTS

HEADER . . . . . . . . . . . . . . . . . . . . . . . . . . . . . . . . . . . . . . . 1

ABSTRACT . . . . . . . . . . . . . . . . . . . . . . . . . . . . . . . . . . . . . . .

PLAIN LANGUAGE SUMMARY . . . . . . . . . . . . . . . . . . . . . . . . . . . . . . . . . . . . . . . . .

BACKGROUND . . . . . . . . . . . . . . . . . . . . . . . . . . . . . . . . . . . . . .

OBJECTIVES . . . . . . . . . . . . . . . . . . . . . . . . . . . . . . . . . . . . . . . . . . .

METHODS . . . . . . . . . . . . . . . . . . . . . . . . . . . . . . . . . . . . . . . 4.4

RESULTS . . . . . . . . . . . . . . . . . . . . . . . . . . . . . . . . . . . 6

Figure 1. . . . . . . . . . . . . . . . . . . . . . . . . . . . . . . . . . . . . . 47

Figure 2. . . . . . . . . . . . . . . . . . . . . . . . . . . . . . . . . . . . . . . . . . 9

Figure 3. . . . . . . . . . . . . . . . . . . . . . . . . . . . . . . . . . . . . . . . . .

Figure $4 . \quad$. . . . . . . . . . . . . . . . . . . . . . . . . . . . . . . . . . . . . 411

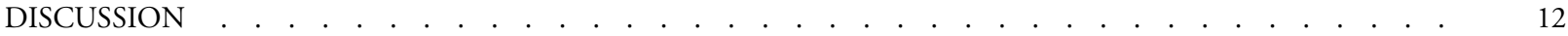

AUTHORS' CONCLUSIONS . . . . . . . . . . . . . . . . . . . . . . . . . . . . . . . . . . . . . . 14

ACKNOWLEDGEMENTS . . . . . . . . . . . . . . . . . . . . . . . . . . . . . . . . . . . . . . . 15

REFERENCES . . . . . . . . . . . . . . . . . . . . . . . . . . . . . . . . . . . . . . 16

CHARACTERISTICS OF STUDIES . . . . . . . . . . . . . . . . . . . . . . . . . . . . . . . . . . . . . . . .

DATA AND ANALYSES . . . . . . . . . . . . . . . . . . . . . . . . . . . . . . . . . . . . . . . . . . . . . . . . . . .

Analysis 1.1. Comparison 1 Enalapril versus placebo, Outcome 1 Development of clinical heart failure. . . . . . . 30

Analysis 1.2. Comparison 1 Enalapril versus placebo, Outcome 2 Dizziness or hypotension. . . . . . . . . . . . . 31

Analysis 1.3. Comparison 1 Enalapril versus placebo, Outcome 3 Rash or hives. . . . . . . . . . . . . . . . 31

Analysis 1.4. Comparison 1 Enalapril versus placebo, Outcome 4 Heart palpitations. . . . . . . . . . . . . . . 32

Analysis 1.5. Comparison 1 Enalapril versus placebo, Outcome 5 Anxiety or depression. . . . . . . . . . . . . . 32

Analysis 1.6. Comparison 1 Enalapril versus placebo, Outcome 6 Headache. . . . . . . . . . . . . . . . . . . . 33

Analysis 1.7. Comparison 1 Enalapril versus placebo, Outcome 7 Gastrointestinal disturbance. . . . . . . . . . . . 33

Analysis 1.8. Comparison 1 Enalapril versus placebo, Outcome 8 Hepatitis C. . . . . . . . . . . . . . . . . . . 34

Analysis 1.9. Comparison 1 Enalapril versus placebo, Outcome 9 Neutropenia. . . . . . . . . . . . . . . . . . . 34

Analysis 1.10. Comparison 1 Enalapril versus placebo, Outcome 10 Musculoskeletal pain. . . . . . . . . . 35

Analysis 1.11. Comparison 1 Enalapril versus placebo, Outcome 11 Dry cough. . . . . . . . . . . . . . . . 35

Analysis 1.12. Comparison 1 Enalapril versus placebo, Outcome 12 Shortness of breath. . . . . . . . . . . 36

Analysis 1.13. Comparison 1 Enalapril versus placebo, Outcome 13 Chest pain. . . . . . . . . . . . . . . . 36

ADDITIONAL TABLES . . . . . . . . . . . . . . . . . . . . . . . . . . . . . . . . . . . . . 36

APPENDICES . . . . . . . . . . . . . . . . . . . . . . . . . . . . . . . . . . . . . . . . . . . . . . .

WHAT'S NEW . . . . . . . . . . . . . . . . . . . . . . . . . . . . . . . . . . . . . . . . . . . . 45

CONTRIBUTIONS OF AUTHORS . . . . . . . . . . . . . . . . . . . . . . . . . . . . . . . . . . . . . . . . . . . .

DECLARATIONS OF INTEREST . . . . . . . . . . . . . . . . . . . . . . . . . . . . . . . . . . . . . . . . . .

SOURCES OF SUPPORT . . . . . . . . . . . . . . . . . . . . . . . . . . . . . . . . . . . . . . . . . . . . . . . . 46

DIFFERENCES BETWEEN PROTOCOL AND REVIEW . . . . . . . . . . . . . . . . . . . . . . . . . 46

INDEX TERMS . . . . . . . . . . . . . . . . . . . . . . . . . . . . . . . . . . . . . 46

Medical interventions for treating anthracycline-induced symptomatic and asymptomatic cardiotoxicity during and after treatment for childhood cancer (Review)

Copyright $\odot 2016$ The Cochrane Collaboration. Published by John Wiley \& Sons, Ltd. 


\title{
[Intervention Review] \\ Medical interventions for treating anthracycline-induced symptomatic and asymptomatic cardiotoxicity during and after treatment for childhood cancer
}

\author{
Daniel KL Cheuk ${ }^{1 a}$, Elske Sieswerda ${ }^{2}$, Elvira C van Dalen ${ }^{2}$, Aleida Postma ${ }^{3}$, Leontien CM Kremer ${ }^{2}$ \\ ${ }^{1}$ Department of Pediatrics and Adolescent Medicine, The University of Hong Kong, Queen Mary Hospital, Hong Kong, China. \\ ${ }^{2}$ Department of Paediatric Oncology, Emma Children's Hospital/Academic Medical Center, Amsterdam, Netherlands. ${ }^{3}$ Department \\ of Paediatric Oncology, University Medical Center Groningen and University of Groningen, Beatrix Children's Hospital, Groningen, \\ Netherlands \\ ${ }^{a}$ Joint first authorship with Elske Sieswerda \\ Contact address: Daniel KL Cheuk, Department of Pediatrics and Adolescent Medicine, The University of Hong Kong, Queen Mary \\ Hospital, Pokfulam Road, Hong Kong, China. cheukkld@hkucc.hku.hk.
}

Editorial group: Cochrane Childhood Cancer Group.

Publication status and date: New search for studies and content updated (no change to conclusions), published in Issue 8, 2016.

Review content assessed as up-to-date: 25 September 2015.

Citation: Cheuk DKL, Sieswerda E, van Dalen EC, Postma A, Kremer LCM. Medical interventions for treating anthracycline-induced symptomatic and asymptomatic cardiotoxicity during and after treatment for childhood cancer. Cochrane Database of Systematic Reviews 2016, Issue 8. Art. No.: CD008011. DOI: 10.1002/14651858.CD008011.pub3.

Copyright (C) 2016 The Cochrane Collaboration. Published by John Wiley \& Sons, Ltd.

\begin{abstract}
A B S T R A C T
Background

Anthracyclines are frequently used chemotherapeutic agents for childhood cancer that can cause cardiotoxicity during and after treatment. Although several medical interventions in adults with symptomatic or asymptomatic cardiac dysfunction due to other causes are beneficial, it is not known if the same treatments are effective for childhood cancer patients and survivors with anthracyclineinduced cardiotoxicity. This review is an update of a previously published Cochrane review.
\end{abstract}

Objectives

To compare the effect of medical interventions on anthracycline-induced cardiotoxicity in childhood cancer patients or survivors with the effect of placebo, other medical interventions, or no treatment.

Search methods

We searched the Cochrane Central Register of Controlled Trials (CENTRAL) (the Cochrane Library, 2015, Issue 8), MEDLINE/ PubMed (1949 to September 2015), and EMBASE/Ovid (1980 to September 2015) for potentially relevant articles. In addition, we searched reference lists of relevant articles, conference proceedings of the International Society for Paediatric Oncology (SIOP), the American Society of Clinical Oncology (ASCO), the American Society of Hematology (ASH), the International Conference on LongTerm Complications of Treatment of Children \& Adolescents for Cancer, and the European Symposium on Late Complications from Childhood Cancer (from 2005 to 2015), and ongoing trial databases (the ISRCTN Register, the National Institutes of Health (NIH) Register, and the trials register of the World Health Organization (WHO); all searched in September 2015).

\section{Selection criteria}

Randomised controlled trials (RCTs) or controlled clinical trials (CCTs) comparing the effectiveness of medical interventions to treat anthracycline-induced cardiotoxicity with either placebo, other medical interventions, or no treatment.

Medical interventions for treating anthracycline-induced symptomatic and asymptomatic cardiotoxicity during and after treatment for childhood cancer (Review)

Copyright $\odot 2016$ The Cochrane Collaboration. Published by John Wiley \& Sons, Ltd. 


\section{Data collection and analysis}

Two review authors independently performed the study selection. One review author performed the data extraction and 'Risk of bias' assessments, which another review author checked. We performed analyses according to the guidelines in the Cochrane Handbook for Systematic Reviews of Interventions.

\section{Main results}

In the original version of the review we identified two RCTs; in this update we identified no additional studies. One trial (135 participants) compared enalapril with placebo in childhood cancer survivors with asymptomatic anthracycline-induced cardiac dysfunction. The other trial (68 participants) compared a two-week treatment of phosphocreatine with a control treatment (vitamin C, adenosine triphosphate, vitamin E, oral coenzyme Q10) in leukaemia patients with anthracycline-induced cardiotoxicity. Both studies had methodological limitations.

The RCT on enalapril showed no statistically significant differences in overall survival, mortality due to heart failure, development of clinical heart failure, and quality of life between treatment and control groups. A post-hoc analysis showed a decrease (that is improvement) in one measure of cardiac function (left ventricular end-systolic wall stress (LVESWS): $-8.62 \%$ change) compared with placebo $(+1.66 \%$ change $)$ in the first year of treatment $(\mathrm{P}=0.036)$, but not afterwards. Participants treated with enalapril had a higher risk of dizziness or hypotension (risk ratio $7.17,95 \%$ confidence interval 1.71 to 30.17 ) and fatigue (Fisher's exact test, $\mathrm{P}=0.013$ ).

The RCT on phosphocreatine found no differences in overall survival, mortality due to heart failure, echocardiographic cardiac function, and adverse events between treatment and control groups.

\section{Authors' conclusions}

Only one trial evaluated the effect of enalapril in childhood cancer survivors with asymptomatic cardiac dysfunction. Although there is some evidence that enalapril temporarily improves one parameter of cardiac function (LVESWS), it is unclear whether it improves clinical outcomes. Enalapril was associated with a higher risk of dizziness or hypotension and fatigue. Clinicians should weigh the possible benefits with the known side effects of enalapril in childhood cancer survivors with asymptomatic anthracycline-induced cardiotoxicity.

Only one trial evaluated the effect of phosphocreatine in childhood cancer patients with anthracycline-induced cardiotoxicity. Limited data with a high risk of bias showed no significant difference between phosphocreatine and control treatments on echocardiographic function and clinical outcomes.

We did not identify any RCTs or CCTs studying other medical interventions for symptomatic or asymptomatic cardiotoxicity in childhood cancer patients or survivors.

High-quality studies should be performed.

\section{PLAIN LANGUAGE SUMMARY}

\section{Treatment for cardiac problems caused by anthracycline chemotherapy for childhood cancer}

Anthracyclines are anticancer drugs used in the treatment of different types of childhood cancer. An important adverse effect of anthracyclines is damage to the heart, which can lead to asymptomatic (without complaints) or symptomatic (with complaints) cardiac problems during and after cancer treatment. While there are several drugs available to treat other types of cardiac problems in adults, it is not known if these drugs are beneficial in treating cardiac problems caused by anthracyclines in childhood cancer patients and survivors. A physician confronted with a childhood cancer patient or survivor with anthracycline-induced cardiac problems should be able to make an informed decision on how to treat this patient based on high-quality evidence about the beneficial and adverse effects of the treatment options. We searched for and summarised studies that evaluated drugs for treating anthracycline-induced cardiac problems in childhood cancer patients and survivors.

We identified two randomised studies evaluating two different drugs in two different types of patients. One of these drugs, an angiotensinconverting enzyme (ACE) inhibitor (enalapril), had a short-term beneficial effect on heart function in survivors of childhood cancer with asymptomatic cardiac problems caused by anthracyclines compared with placebo. However, the drug had no significant beneficial effect on other important outcomes and was associated with side effects such as dizziness and fatigue. This study was of reasonable/good quality. The other study was of low quality and found no effect of a short treatment with phosphocreatine in childhood leukaemia patients with

Medical interventions for treating anthracycline-induced symptomatic and asymptomatic cardiotoxicity during and after treatment for 2 childhood cancer (Review)

Copyright $\odot 2016$ The Cochrane Collaboration. Published by John Wiley \& Sons, Ltd. 
symptomatic or asymptomatic cardiac problems compared with a control treatment with vitamin C, adenosine triphosphate, vitamin E, and oral coenzyme Q10.

We could make no definitive conclusions about treatment options for anthracycline-induced cardiac problems in childhood cancer patients and survivors. High-quality studies are needed to determine if there are drugs that improve heart function in these patients.

\section{B A C K G ROU N D}

\section{Description of the condition}

Anthracyclines are frequently used chemotherapeutics for childhood cancer that can cause serious cardiac dysfunction (Lefrak 1973; Van Dalen 2014; Von Hoff 1977). This so-called anthracycline-induced cardiotoxicity can develop during, or many years after, treatment and may present clinically, with symptoms of heart failure (Mulrooney 2009; Van der Pal 2012), or subclinically, with abnormalities found only in diagnostic tests (Ganame 2007; Lipshultz 1991; Van Dalen 2006a). It is estimated that almost $10 \%$ of childhood cancer patients treated with anthracycline doses of $300 \mathrm{mg} / \mathrm{m}^{2}$ or more will eventually develop symptomatic cardiotoxicity, a condition that is associated with high morbidity and mortality (Steinherz 1995; Van Dalen 2006a). Asymptomatic signs of cardiotoxicity are found in up to $57 \%$ of survivors of childhood cancer and are often progressive over time, but the long-term prognosis of these abnormalities is not known (Kremer 2002; Lipshultz 2005a; Sorensen 2003). In the general adult population, individuals with asymptomatic cardiac dysfunction are at increased risk of developing symptomatic heart failure and death (Wang 2003). These findings raise the concern that children and young adults with asymptomatic cardiac dysfunction caused by anthracyclines are also at risk of progression to symptomatic heart failure in the long term.

\section{Description of the intervention}

Several cardiovascular drugs have been studied in people with cardiac dysfunction due to other causes. Studies in adults with symptomatic as well as asymptomatic heart failure due to causes other than anthracyclines have shown that treatment of an average duration of three years with angiotensin-converting enzyme (ACE) inhibitors reduces long-term morbidity and mortality, regardless of the aetiology of heart failure (Abdulla 2006; Garg 1995; Jong 2003; SOLVD 1991; SOLVD 1992). The Studies of Left Ventricular Dysfunction (SOLVD) also showed an improvement in quality of life in symptomatic participants and no negative effect in quality of life in asymptomatic participants (Rogers 1994; SOLVD
1991; SOLVD 1992). A cost-effectiveness study was performed in symptomatic SOLVD patients and showed survival benefit as well as cost savings (Glick 1995). Treatment with beta-blocking agents in addition to an ACE inhibitors improves the mortality outcome in people with symptomatic cardiac failure (CIBIS-II 1999; Foody 2002; Packer 1996a; Packer 1996b; Waagstein 1993), and improves cardiac function in people with asymptomatic heart failure (Colucci 2007; Exner 1999). Other medical interventions may also potentially improve the prognosis of people with symptomatic or asymptomatic heart failure, such as angiotensin receptor blockers (Granger 2003 and Maggioni 2002), or combinations of heart failure medications, such as angiotensin receptor blockers, ACE inhibitors, and beta-blockers (Cohn 2001; McMurray 2003).

\section{Why it is important to do this review}

Many collaborative groups have advocated screening for cardiac dysfunction in childhood cancer patients and survivors (Armenian 2014; Armenian 2015; COG 2006; Sieswerda 2012; SIGN 2013; Skinner 2005; Steinherz 1992). However, for appropriate screening for a disease, an effective treatment should be available (Wilson 1968). In addition, physicians who are confronted with childhood cancer patients and survivors with cardiac dysfunction should be able to make a well-informed decision regarding the risks and benefits of treatment options. The optimal treatment for people with anthracycline-induced cardiotoxicity, and how to decrease morbidity and mortality, are currently unclear (Lipshultz 2002; Silber 2004; Van Dalen 2003). Although medical interventions in populations with symptomatic and asymptomatic heart failure due to causes other than anthracyclines are beneficial, we cannot assume that the efficacy of this treatment is similar in childhood cancer patients and survivors (Kay 2001; Shaddy 2007). The different aetiology of the cardiac dysfunction, as well as the different age distribution, make it necessary to study the benefits and risks of treatment of symptomatic and asymptomatic anthracycline-induced cardiotoxicity in this specific population. Treatment of people with anthracycline-induced cardiotoxicity should ideally decrease morbidity and mortality, improve cardiac function, reverse disease progression, and improve quality of life.

This is an update of the first systematic review, Sieswerda 2011,

Medical interventions for treating anthracycline-induced symptomatic and asymptomatic cardiotoxicity during and after treatment for 3 childhood cancer (Review)

Copyright $\Subset 2016$ The Cochrane Collaboration. Published by John Wiley \& Sons, Ltd. 
evaluating the current available evidence on medical interventions in both symptomatic and asymptomatic anthracycline-induced cardiotoxicity during and after treatment for childhood cancer.

\section{O B J E C T I V E S}

To compare the effect of medical interventions on anthracyclineinduced cardiotoxicity in childhood cancer patients or survivors with the effect of placebo, other medical interventions, or no treatment.

\section{METHODS}

\section{Criteria for considering studies for this review}

\section{Types of studies}

Randomised controlled trials (RCTs) and controlled clinical trials (CCTs) (as defined by the Cochrane Handbook for Systematic Reviews of Interventions (Higgins 2008)), including non-inferiority and cross-over trials, comparing a medical intervention for treating anthracycline-induced cardiotoxicity with either placebo, other medical intervention(s), or no treatment.

\section{Types of participants}

Patients and survivors (previously) diagnosed with any type of childhood cancer (defined as a diagnosis of cancer at age 18 years or younger) and with symptomatic or asymptomatic anthracycline-induced cardiotoxicity. RCTs or CCTs including both children and adults were only eligible for inclusion in this review if the majority of participants were 18 years or younger at cancer diagnosis. Anthracycline-induced cardiotoxicity, as defined by the authors of the original study, could be diagnosed both during and after anthracycline treatment for childhood cancer. Due to the low number of patients expected, we did not exclude patients who also had been treated with mediastinal radiotherapy.

\section{Types of interventions}

Medical (that is drug) interventions given with the intention to change the course of anthracycline-induced symptomatic or asymptomatic cardiotoxicity. We excluded surgical interventions such as heart transplantation.

\section{Types of outcome measures}

\section{Primary outcomes}

1. Overall survival.

2. Mortality due to heart failure.

3. Development of clinical heart failure as defined by authors.

4. Occurrence of adverse events and tolerability as defined by authors.

\section{Secondary outcomes}

1. Change in cardiac function measured by different diagnostic tests as defined by authors.

2. (Duration of) hospitalisation for heart failure.

3. Change in NYHA (New York Heart Association) stage of heart failure (NYHA 1994).

4. Change in quality of life as defined by authors.

5. Costs as defined by authors.

Outcomes may have been assessed at any time during follow-up.

\section{Search methods for identification of studies}

\section{Electronic searches}

We searched the Cochrane Central Register of Controlled Trials (CENTRAL) (the Cochrane Library, 2015, Issue 8), MEDLINE/PubMed (1949 to 25 September 2015), and EMBASE/ Ovid (1980 to 25 September 2015) for potentially relevant articles.

The search strategies for CENTRAL, MEDLINE/PubMed, and EMBASE/Ovid are shown in Appendix 1, Appendix 2, and Appendix 3. We used the highly sensitive search strategy for identifying reports of RCTs and CCTs (sensitivity-maximizing version) as described in the Cochrane Handbook for Systematic Reviews of Interventions (Higgins 2008).

We scanned the ISRCTN Register (www.isrctn.com), the National Institutes of Health (NIH) Register (www.clinicaltrials.gov), and the trials register of the World Health Organization (WHO) ( apps.who.int/trialsearch/) on 29 September 2015. The search keywords are shown in Appendix 4.

There were no language restrictions.

\section{Searching other resources}

We located information about trials not registered in CENTRAL, MEDLINE/PubMed, or EMBASE/Ovid, either published or unpublished, by searching the reference lists of relevant articles and review articles. In addition, we handsearched conference proceedings of the International Society for Paediatric Oncology (SIOP), 
the American Society of Clinical Oncology (ASCO), the American Society of Hematology (ASH), the International Conference on Long-Term Complications of Treatment of Children \& Adolescents for Cancer, and the European Symposium on Late Complications from Childhood Cancer from 2005 up to and including 2015. Again, there were no language restrictions. The search keywords are shown in Appendix 5.

\section{Data collection and analysis}

\section{Selection of studies}

After employing the search strategy described above, two review authors independently identified studies meeting the criteria for this review. We obtained in full any study which seemed to meet the inclusion criteria on the grounds of the title, abstract, or both for closer inspection. The review authors included or excluded studies for this review based on full-text assessment. Two studies selected for full-text evaluation were not in a language the authors were familiar with; for these, we contacted Cochrane collaborators from Russia and China, who individually determined if the studies were eligible. We recorded the reasons for exclusion of any study considered for the review. Discrepancies in the selection process were resolved between authors by consensus, or in case of doubt, by consulting a third-party arbitrator.

One review author performed the search of reference lists of relevant articles and review articles, as well as the search within the conference proceedings.

We have constructed a flow diagram.

\section{Data extraction and management}

One review author performed data extraction using standardised forms, which a second review author checked. For the study published in Chinese, this was done by a review author from China based on full text and checked by another review author based on the abstract only. We abstracted information on the following items:

1. study design;

2. 'Risk of bias' items;

3. number of study participants;

4. participants, including:

i) age at diagnosis;

ii) age at study entry;

iii) sex;

iv) time since diagnosis;

v) study performed during cancer treatment or in survivors;

vi) in case of survivors, time since end of cancer treatment;

vii) prior anthracycline treatment, including:

a) type of anthracycline; b) cumulative anthracycline dose;

viii) other previous treatment, including:

a) chemotherapy;

b) cardioprotective interventions;

c) radiotherapy on heart region;

ix) comorbidities, including:

a) cardiovascular disease (specification disease, cause and duration of disease before start of intervention);

b) other (specification disease, cause and duration of disease before start of intervention);

$\mathrm{x})$ other treatment, including:

a) other cardiovascular medication (agent, dose, frequency, mode of administration, and duration);

b) other medication (agent, dose, frequency, mode of administration, and duration);

c) cardiovascular surgery (location and procedure);

5. interventions, including:

i) type of medical intervention (substance name, brand name);

ii) dose and frequency of medical intervention;

iii) mode of administration (oral, intravenous, etc.);

iv) duration of medical intervention;

v) duration between diagnosis of anthracycline-induced cardiotoxicity and start of medical intervention;

6. outcome measures, including:

i) outcome definition;

ii) timing of outcome measurement;

7. length of follow-up.

In cases of disagreement, we re-examined the abstracts and articles and discussed the topic until consensus was achieved. No thirdparty arbitration was needed.

\section{Assessment of risk of bias in included studies}

One review author assessed the risk of bias using a standardised form, which was checked by another review author. The study published in Chinese was assessed by a review author from China based on full text and checked by another review author based on the (English) abstract only. We evaluated the studies according to the following criteria: generation of allocation sequence, concealment of treatment allocation, blinding of the study participants, blinding of personnel, blinding of outcome assessors, completeness of follow-up, intention-to-treat (ITT) analysis, selective outcome reporting, and other sources of bias. We determined the items blinding of outcome assessors, completeness of follow-up, and ITT analysis for all reported study outcomes. Only for overall survival, we regarded blinding of the outcome assessor not relevant. For all 'Risk of bias' items, we used definitions based on the module of Cochrane Childhood Cancer at the time our protocol was published (Module CCG), and on the Cochrane Handbook for Systematic Reviews of Interventions (Higgins 2008) (see additional Table 1). We resolved discrepancies between authors by consensus. 
In case of doubt, we consulted a third-party arbitrator.

\section{Measures of treatment effect}

We related dichotomous outcomes to risk using the risk ratio (RR) and presented all results with the corresponding 95\% confidence interval (CI). When only one study was available and there were no events in one of the treatment groups, it was not appropriate to calculate the RR, its 95\% CI, and the corresponding P value. For these outcomes, we calculated the Fisher's exact P value instead, using PASW Statistics (SPSS) for Windows version 18 (SPSS Inc., Chicago, IL, USA). We planned to analyse continuous outcomes using the mean difference (MD). However, this was not possible since no standard deviation (SD) of change in the continuous outcomes was provided by the included studies. For the assessment of survival, we planned to use Parmar's method if hazard ratios had not been explicitly presented in the study (Parmar 1998). However, this was not applicable, since we could not pool the included studies.

\section{Dealing with missing data}

When information relevant to study selection was missing, we attempted to contact the authors in order to obtain the missing data.

We extracted data by allocated intervention, irrespective of compliance with the allocated intervention, in order to allow an ITT analysis. If this was not possible, we stated this and performed an as-treated analysis.

\section{Assessment of heterogeneity}

Assessing heterogeneity was not applicable, since we did not pool the included studies.

\section{Assessment of reporting biases}

We were not able to construct a funnel plot to evaluate the existence of publication bias graphically (Higgins 2008), since we included only two trials in this review and pooling of results was not possible. As a rule of thumb, tests for funnel plot asymmetry should be used only when there are at least 10 studies included in the metaanalysis. When there are fewer studies, the power of the tests is too low to distinguish chance from real asymmetry (Higgins 2008).

\section{Data synthesis}

We entered the data into RevMan 5.3 (RevMan 2014), and analysed according to the guidelines of the Cochrane Handbook for Systematic Reviews of Interventions (Higgins 2008). We used a random-effects model for the estimation of treatment effects throughout the review.
We included outcome measures in this systematic review only if it was the intention of the study authors to perform the necessary assessments in all randomised participants (that is not optional or only performed in some centres). When less than $50 \%$ of the participants in a study had an acceptable follow-up for a particular outcome measure, due to the associated high risk of attrition bias we did not report the results of this outcome measure.

We did not perform a pooled analysis since the included trials were not comparable with regard to important study characteristics, that is age, sex, cardiac dysfunction, treatment used, outcome definitions, and length of follow-up. We therefore summarised the results descriptively.

We planned to analyse data separately for clinical heart failure alone versus no clinical heart failure and for clinical and subclinical cardiotoxicity combined versus normal heart function. However, this was not applicable, since pooling was not possible and the study that included both participants with clinical and subclinical heart failure did not provide enough information to allow for such an analysis.

\section{Subgroup analysis and investigation of heterogeneity}

We hypothesised that treatment with mediastinal radiotherapy could cause other cardiac pathology, such as heart valve problems, and that it is therefore possible that treatment effects would differ between patients treated with and without mediastinal radiotherapy. However, we were not able to investigate this type of heterogeneity by performing a subgroup analysis with regard to previous mediastinal radiotherapy because pooling was not possible and because the individual studies did not provide outcomes separately for participants treated with and without previous radiotherapy.

\section{Sensitivity analysis}

Since we could not pool results, performing a sensitivity analysis using the 'Risk of bias' criteria was not applicable.

\section{RES U L T S}

\section{Description of studies}

\section{Results of the search}

Our original searches in the electronic databases CENTRAL, MEDLINE/PubMed, and EMBASE/Ovid identified 1429 titles with or without an abstract. In the update search of these electronic databases, we identified an additional 480 titles (442 records after removal of duplicates) (Figure 1), of which we selected eight references reporting on five studies for full-text assessment. No 
additional reference in the update search was selected for full-text assessment. We did not include the remaining 1863 papers because they were not RCTs or CCTs, were laboratory studies, animal studies, did not include children with cancer or survivors of childhood cancer, or were preventive intervention studies of people without signs of cardiotoxicity. While examining the reference lists of relevant papers, we found an additional five papers, reporting on two studies (of which one was already identified in the electronic database search), which we also assessed in full text. We identified no new studies in the current update search. In total, we assessed the full text of 13 papers reporting on seven studies.

Figure I. Study flow diagram.

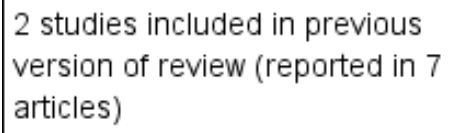

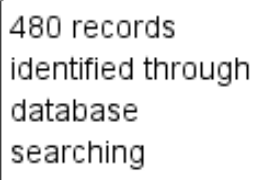

0 additional records identified through searching reference lists, conference proceedings, and ongoing_trial registers

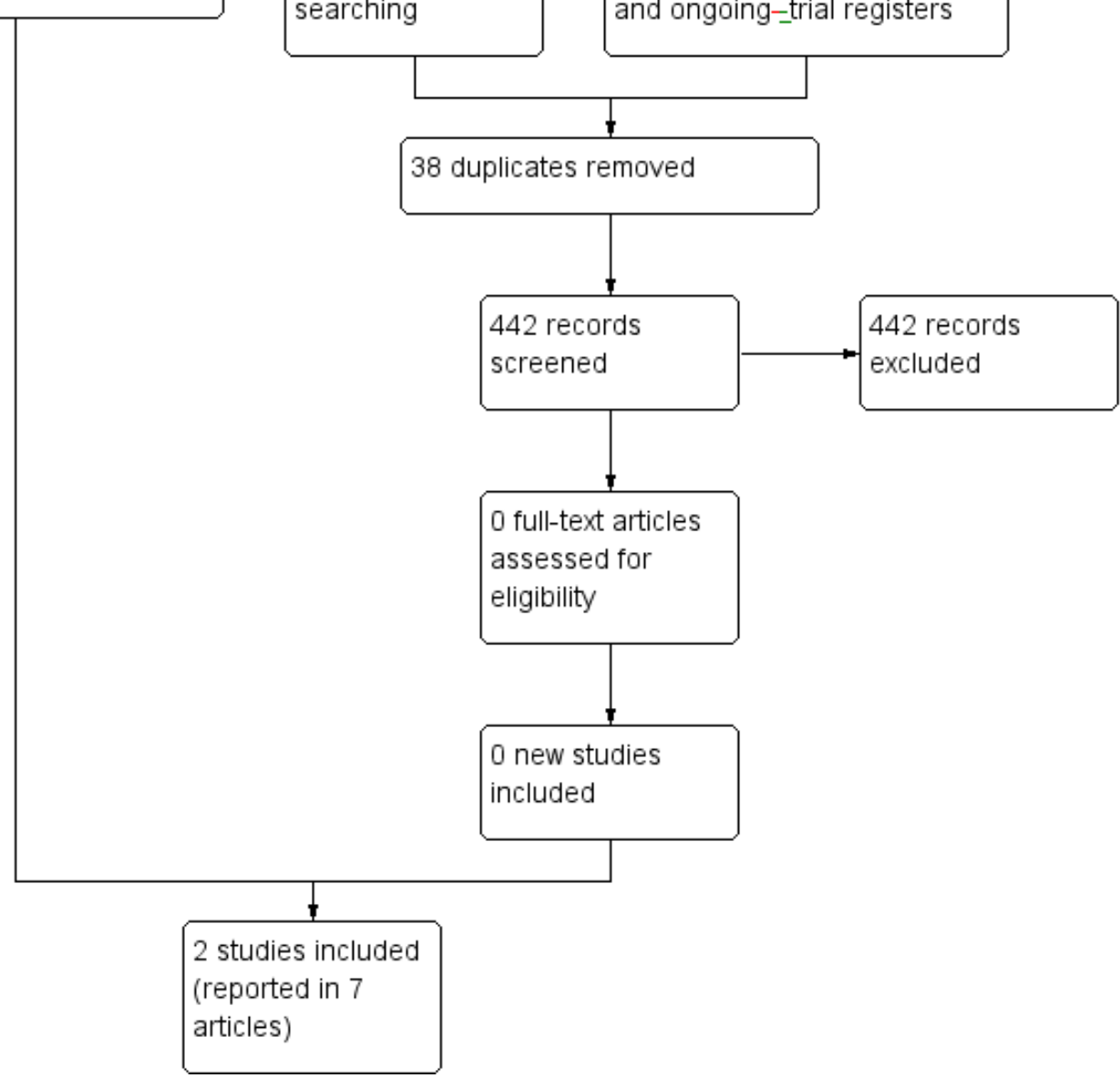

Medical interventions for treating anthracycline-induced symptomatic and asymptomatic cardiotoxicity during and after treatment for 
Based on full-text assessment, we finally included in this review seven papers reporting on two studies. We excluded six papers reporting on five studies. We have listed reasons for exclusion in the Characteristics of excluded studies table.

By scanning the conference proceedings of relevant conferences, we identified two papers that have not yet been published in full text and are awaiting further assessment (see the Characteristics of studies awaiting classification table). By scanning the ongoing trials databases, we identified one additional ongoing trial (see the Characteristics of ongoing studies table). We identified no additional studies in the current update search of conference proceedings and trials databases.

\section{Included studies}

We included two RCTs with a total of 203 participants in the review (Chen 2008; Silber 2004); we identified no new studies in the current update. Six papers provided information on one trial (see all references under Silber 2004). We extracted information about the study from all six papers.

In one trial, 69 participants received enalapril and 66 participants received placebo (Silber 2004). Participants were childhood cancer survivors with asymptomatic decline of cardiac function at some time during follow-up after anthracycline exposure. Followup time was a median of 2.80 (range 2 weeks to 6.1 years).

In the other trial, 35 participants received phosphocreatine and 33 participants received a control treatment with vitamin $\mathrm{C}$, adenosine triphosphate (ATP), vitamin E, and oral coenzyme Q10 (Chen 2008). Participants were children with acute leukaemia and anthracycline-induced cardiotoxicity, part of which was symptomatic. The duration of treatment was 14 days, and assessment of cardiac function was performed one day after the end of treatment; it is unclear if there was longer follow-up, for example for the clinical outcomes.

For more information see the Characteristics of included studies table.

\section{Excluded studies}

The number of excluded papers based on full-text evaluation was six in total, reporting on five studies. A summary of the excluded studies can be found in the Characteristics of excluded studies table.

\section{Risk of bias in included studies}

We have summarised the evaluation of the risk of bias in the included studies below. An additional overview of evaluation in each domain per included study is provided in the Characteristics of included studies table ('Risk of bias' section) and summarised in Figure 2.

Medical interventions for treating anthracycline-induced symptomatic and asymptomatic cardiotoxicity during and after treatment for 
Figure 2. Risk of bias summary: review authors' judgements about each risk of bias item for each included study.

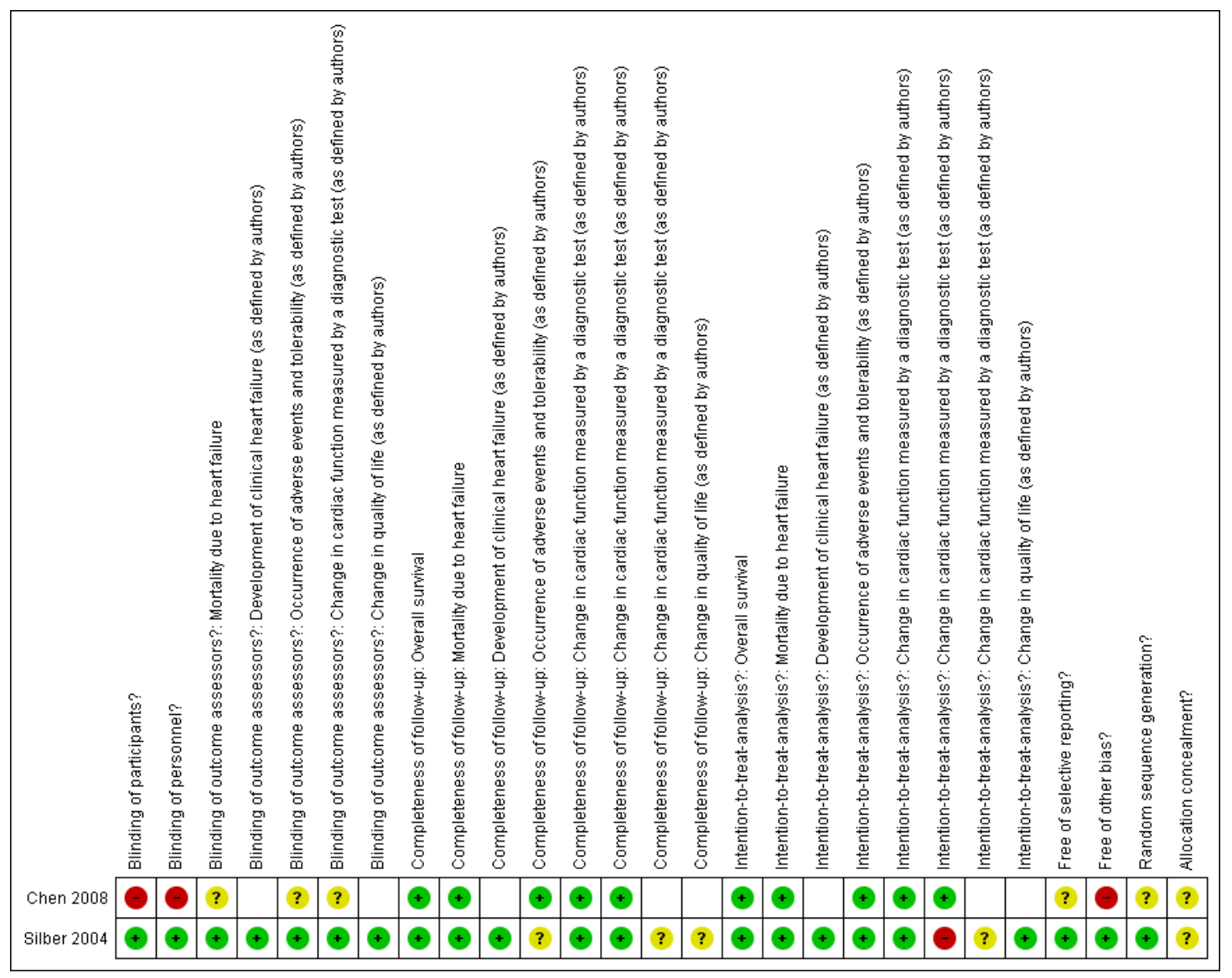

\section{Allocation}

In the enalapril study, allocation to treatment or control group was at random. For the allocation sequence, random permuted blocks with equal allocation were used within each stratum of prespecified variables (Silber 2004). Allocation was described as concealed, but the method of allocation concealment was not stated and was therefore unclear.

In the phosphocreatine study, allocation to treatment or control group was also at random, but the method used to generate the allocation sequence was not described (Chen 2008). It was not stated if there was allocation concealment.

\section{Blinding}

The enalapril trial was reported to be a double-blind study (Silber 2004). Although how the blinding was done was not clearly described, one of the additional papers concerning the trial stated that participants truly did not know which of the two treatments they had received (Silber 2004), indicating that blinding of participants was effective. It was also clearly stated that investigators were blinded to the intervention. However, it was not specified if the blinding of investigators concerned personnel as well as outcome assessors, if it was applicable to all studied outcomes, or if it was effective. Based on the effectiveness of blinding of participants and the statement that participants and investigators were blinded, we judged that this probably was the case. We consulted a third party regarding this judgement, who agreed with it.

In the phosphocreatine trial, blinding was not described and based on the different types of route of administration per treatment and control group, we judged that blinding of participants and personnel was very unlikely (Chen 2008). It was not stated if the investigators or outcome assessors were blinded, and we therefore we judged it to be unclear.

Medical interventions for treating anthracycline-induced symptomatic and asymptomatic cardiotoxicity during and after treatment for childhood cancer (Review)

Copyright $\odot 2016$ The Cochrane Collaboration. Published by John Wiley \& Sons, Ltd. 


\section{Incomplete outcome data}

In the enalapril trial, follow-up was complete for overall survival, mortality due to heart failure, and development of clinical heart failure (Silber 2004). Follow-up was complete for change in cardiac function for the study outcomes maximal cardiac index (MCI) and left ventricular end-systolic wall stress (LVESWS), which were both measured in at least one post-baseline measurement in more than $80 \%$ of the participants. However, it should be noted that it was unclear if follow-up was complete for these parameters at the end of follow-up. For other measures of cardiac function (shortening fraction (SF) and stress-velocity index (SVI)) and the other outcomes that were reported (occurrence of adverse events and change in quality of life), it was unclear if the follow-up was complete. One of the additional papers concerning this trial stated that a considerable fraction of the study participants ended participation, but did not report exact numbers and timing of study dropouts (Silber 2004). It was clearly stated that intention-totreat (ITT) analysis was performed for the trial's primary and secondary outcomes. An extra per-protocol analysis was performed on LVESWS. For the other measures of cardiac function (SF and SVI) it was unclear if an ITT analysis was performed. For overall survival, mortality due to heart failure, development of clinical heart failure, change in quality of life, and occurrence of adverse events, ITT analysis was possible, since the treatment allocation was abstractable for the reported outcomes.

In the phosphocreatine trial, complete assessment was done for overall survival, mortality due to heart failure, and occurrence of adverse events (Chen 2008). For change in cardiac function, two parameters (echocardiography and hyper-sensitivity C-reactive protein (hsCRP)) were reported in all participants, while the other parameters of change in cardiac function outcomes (electrocardiogram (ECG), creatine kinase $(\mathrm{CK})$, creatine kinase $\mathrm{MB}$ (CK-MB), lactate dehydrogenase (LDH1), and alpha hydroxybutyrate dehydrogenase (alphaHBDH)) were only assessed in some participants and therefore not reported in this review. For overall survival, mortality due to heart failure, two parameters of change in cardiac function (echocardiography and hsCRP), and the occurrence of adverse events, ITT analysis was possible, since the treatment allocation was abstractable for all reported outcomes.

\section{Selective reporting}

There was no sign of selective reporting in the enalapril trial (Silber 2004). A protocol was published that presented the outcomes that were planned to be studied as well as the planned data analyses (Silber 2004). All outcomes were reported and the analyses done in the final report (Silber 2004). The authors clearly explained that they performed some additional analyses based on exploration of the data.

In the phosphocreatine trial, there was no published protocol, and we therefore cannot exclude selective reporting bias in the study (Chen 2008).

\section{Other potential sources of bias}

In the enalapril trial, we were not aware of other potential issues that could put the study at a high risk of bias (Silber 2004).

In the phosphocreatine study, we had concerns about the comparability of the study participants, especially with regard to potential confounders such as gender, age, cumulative anthracycline dose, type of anthracycline, other cardiotoxic treatment, number of symptomatic participants, and the provision of other treatments during the study (Chen 2008).

\section{Effects of interventions}

Both trials did not allow data extraction for all endpoints. See the Characteristics of included studies table for a more detailed description of the extractable endpoints of each study.

\section{Overall survival and mortality due to heart failure}

We could extract data on overall survival and mortality due to heart failure from both studies.

In the enalapril trial, there were no deaths in both the intervention and the control group during the study (Silber 2004). However, one participant from the placebo group (1.5\%) died eight months after the end of the study, as a result of congestive heart failure. As it was unclear if both the intervention group and placebo group had been followed beyond the end of the study, we did not calculate a risk ratio $(\mathrm{RR})$ of death due to heart failure including this late death.

In the phosphocreatine trial, there were no deaths in both the intervention and the control group during the study (Chen 2008).

\section{Development of clinical heart failure (as defined by authors)}

The enalapril trial provided data on the occurrence of clinical heart failure, which the authors predefined as a clinically significant decline in cardiac performance (Silber 2004). In the intervention group, one participant (1\%) developed such a significant decline, while in the control group this occurred in six (9\%) participants (RR 0.16, 95\% confidence interval (CI) 0.02 to 1.29 ; $\mathrm{P}=0.09$ ). See also Analysis 1.1 and Figure 3. 
Figure 3. Forest plot of comparison: I Enalapril versus placebo, outcome: I.I Development of clinical heart failure.

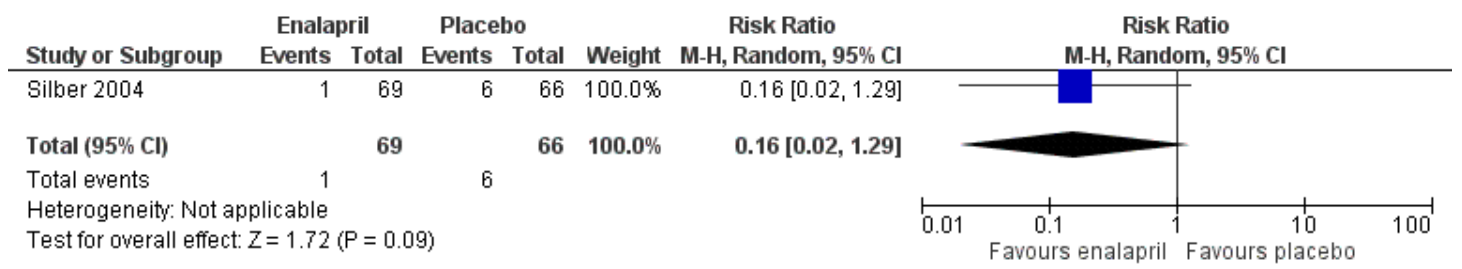

\section{Occurrence of adverse events and tolerability (as defined by authors)}

Both studies reported on the occurrence of adverse events. Neither study reported severity or grading.

In the enalapril trial, all participants were evaluated on the occurrence of adverse events (Silber 2004). The number of adverse events in participants was presented per adverse event, and many events were recorded (see Analysis 1.2 until Analysis 1.13 for RRs

and corresponding 95\% CI, and Table 2 for Fisher's exact P values in outcomes with no event in one of the two groups). A notable difference in adverse events between groups was the higher occurrence of dizziness or hypotension (RR 7.17, $95 \%$ CI 1.71 to 30.17 ; $\mathrm{P}=0.007$; Analysis 1.2; Figure 4) and fatigue (Fisher's exact test, $\mathrm{P}=0.013$; Table 2) in the enalapril group. Other reported adverse events were not statistically different between groups (Analysis 1.3 until Analysis 1.13, and Table 2).

Figure 4. Forest plot of comparison: I Enalapril versus placebo, outcome: I.2 Dizziness or hypotension.

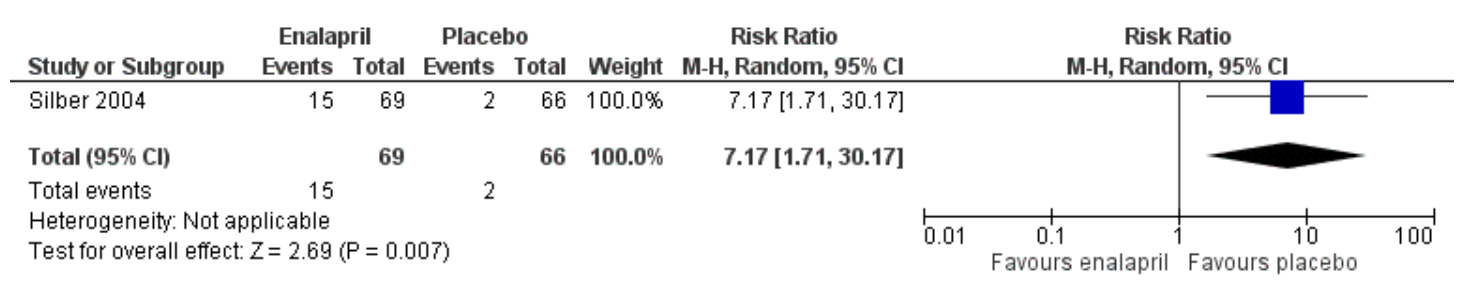

In the phosphocreatine trial, all participants were also evaluated for adverse events (Chen 2008), however it was not stated what type of adverse events were assessed. No adverse events were found in participants of either the phosphocreatine group or the control group during the trial.

\section{Change in cardiac function measured by a diagnostic test}

Both studies provided several measures of change in cardiac function in the treatment and control groups.

The enalapril trial presented their results in unadjusted and adjusted linear mixed models of the change over time of MCI, LVESWS, SVI, and SF (Silber 2004). As the authors did not present dichotomous outcomes, we were unable to calculate RRs and therefore have described the outcomes as presented in the original study (reported as ITT analyses). All analyses were adjusted for anthracycline dose, age at diagnosis, follow-up time, gender, and cardiac irradiation. No differences were detected in the rate of change of all outcome parameters between intervention and control groups (adjusted model coefficient and $\mathrm{P}$ value of effect of enalapril: MCI 0.17, P = 0.36; LVESWS $-1.41, \mathrm{P}=0.24$; SVI $0.004, \mathrm{P}=0.68 ; \mathrm{SF} 0.07, \mathrm{P}=0.81$ ). After the data became available, the study authors explored the data and subsequently performed a piecewise linear model on LVESWS. In this per-protocol analysis (adjusted for the same covariates) they found that enalapril caused a decrease (that is improvement) in LVESWS ($8.62 \mathrm{~g} / \mathrm{cm}^{2}$ change) compared with placebo $\left(+1.66 \mathrm{~g} / \mathrm{cm}^{2}\right.$ change) in the first year of treatment $(P=0.036)$. After the first year there was no statistically significant difference in LVESWS change between enalapril and placebo groups $\left(-0.30\right.$ versus $+0.49 \mathrm{~g} / \mathrm{cm}^{2}, P$ $=0.56$ ).

In the phosphocreatine trial, complete baseline and outcome parameters were provided for echocardiographic cardiac function

Medical interventions for treating anthracycline-induced symptomatic and asymptomatic cardiotoxicity during and after treatment for I I 
and the cardiac marker hsCRP (Chen 2008). All participants had normal echocardiograms before and at the end of treatment (not further specified). In the phosphocreatine group, mean (standard deviation (SD)) baseline levels of hsCRP were 8.79 (1.36) $\mathrm{mg} /$ L compared with $7.88(2.08) \mathrm{mg} / \mathrm{L}$ in the control group, while post-treatment levels were $2.23(0.82) \mathrm{mg} / \mathrm{L}$ in the phosphocreatine group compared with $4.2(1.52) \mathrm{mg} / \mathrm{L}$ in the control group. Since the SDs of the difference before and after treatment within each group were not provided, we could not estimate the mean difference. It is therefore unclear if the change in hsCRP was significantly different between treatment groups. For the cardiac enzymes CK, CK-MB, LDH1, and alphaHBDH, only post treatment levels were provided and are therefore not presented in this review. For the outcomes ECG, troponin I and the combined outcome of all cardiac enzymes together (hsCRP, CK, CK-MB, LDH1, alphaHBDH, troponin I), numbers of participants with normal or abnormal outcomes after the intervention were only provided for those participants with abnormal values at baseline. Since these outcomes were only assessed in a specific subgroup of the studied cohort, we did not present them in this review.

\section{(Duration of) hospitalisation for heart failure}

None of the studies provided outcome data on the (duration of) hospitalisation for heart failure.

\section{Change in NYHA (New York Heart Association) stage for heart failure}

None of the studies provided change in NYHA stage for heart failure as an outcome parameter.

The phosphocreatine trial did provide change in symptoms after the intervention for the participants with symptoms at baseline (Chen 2008). However, since this outcome was reported in less than $50 \%$ of the participants, we did not present these data in this review.

\section{Change in quality of life (as defined by authors)}

The enalapril study provided some information on quality of life (Silber 2004). There were no differences between groups on any of the dimensions of the Short-Form 36 General Health Survey or the Childhood Health Questionnaire-85. No further information was provided.

\section{Costs as defined by authors}

None of the included studies provided outcome data on costs.

\section{DISCUSSION}

As a result of survival rates of childhood cancer patients now approximating $75 \%$, there is a steadily growing group of young childhood cancer survivors who are faced with asymptomatic or even symptomatic anthracycline-induced cardiac dysfunction. Many collaborative groups have advocated screening for cardiac dysfunction in childhood cancer patients and survivors (Armenian 2014; Armenian 2015; COG 2006; Sieswerda 2012; SIGN 2013; Skinner 2005). However, for appropriate screening for a disease, an effective treatment should be available (Wilson 1968). In addition, physicians who are confronted with childhood cancer patients and survivors with cardiac dysfunction should be able to make a well-informed decision regarding the risks and benefits of treatment options. Although ACE inhibitors and beta-blockers improve subclinical and clinical outcomes in adult populations with symptomatic and asymptomatic cardiac dysfunction due to other causes (Abdulla 2006; CIBIS-II 1999; Foody 2002; Garg 1995; Jong 2003; Packer 1996a; Packer 1996b; SOLVD 1991; Waagstein 1993), the different aetiology makes it difficult to extrapolate these beneficial effects to childhood cancer patients and survivors with anthracycline-induced cardiotoxicity. This is an update of the first systematic review, Sieswerda 2011, summarising all evidence on medical interventions for anthracycline-induced cardiotoxicity in childhood cancer patients and survivors.

For a reliable evaluation of the effects of medical interventions for the treatment of anthracycline-induced cardiotoxicity, the best study design is an RCT in which the only difference between the intervention and control group is the use of the medical intervention. However, because of the relative rareness of childhood cancer and therefore of survivors with cardiac dysfunction, we expected to find a low number of studies and therefore decided that both RCTs and CCTs were eligible for this review, keeping in mind the limitations of CCTs.

We identified two eligible RCTs investigating different medical interventions in different study populations and with different lengths of follow-up; in the update we identified no new studies. Since for both medical interventions only one study was available, we could make no definitive conclusions about their effects on anthracycline-induced cardiotoxicity. One RCT on enalapril in childhood cancer survivors with asymptomatic anthracyclineinduced cardiotoxicity showed no significant effect of enalapril on overall survival, mortality due to heart failure, development of clinical heart failure, and quality of life compared with placebo (Silber 2004). Only a post-hoc, per-protocol analysis done by the study investigators themselves showed an improvement in a measure of cardiac function (LVESWS) in the enalapril group compared with the placebo group in the first year of treatment. No effect was found after one year for this or other echocardiographic parameters of cardiac function over time. Participants treated with enalapril had a higher risk of dizziness or hypotension and fatigue. We could make no conclusions about the effect of enalapril on (duration) of hospitalisation, change in NYHA stage of heart fail- 
ure, and costs, since these outcomes were not studied. The other RCT, on phosphocreatine in children with acute leukaemia and symptomatic or asymptomatic anthracycline-induced cardiotoxicity, showed no significant differences in overall survival, mortality due to heart failure, echocardiographic cardiac function, and adverse events compared with a control treatment with vitamin C, ATP, vitamin E, and oral coenzyme Q10 (in all outcomes no events/abnormalities in both groups) (Chen 2008). The effect of the intervention on one marker (hsCRP) was unclear. The study did not report on development of clinical heart failure, (duration of) hospitalisation for heart failure, change in NYHA stage for heart failure, or costs. We could therefore draw no conclusions for these outcomes.

It should be noted that the reasons for not finding significant beneficial effects in the enalapril trial could be due to the low number of participants (that is low power) and participant compliance and loss to follow-up (Silber 2004). Also, the fact that there was a low threshold for patients to be classified as having anthracyclineinduced cardiotoxicity could have influenced the identified effects of treatment. Patients with minor and sometimes temporary abnormalities were included, in which large benefits of the intervention were unlikely. In the SOLVD trial on enalapril in adults with asymptomatic cardiac dysfunction due to other causes than anthracyclines (SOLVD 1992), a clear benefit of enalapril was found on the occurrence of clinical heart failure. This trial had a much larger sample size (4228 participants) and used a more strict definition to classify patients as having cardiac dysfunction (that is a left ventricular ejection fraction (LVEF) of $35 \%$ or less). The enalapril trial had a relatively short length of follow-up (median 2.80 years). It is therefore unknown if there is a beneficial effect of enalapril in the longer term. In comparison, a follow-up study of the earlier mentioned SOLVD trial showed beneficial effects of enalapril treatment on mortality during a 12-year follow-up (Jong 2003; SOLVD 1992). In the phosphocreatine trial (Chen 2008), reasons for not identifying significant effects of the intervention could also be the low power and the very short duration of treatment and presumably also maximum follow-up (that is 14 days). Also, the most optimal dosage schedule of phosphocreatine is currently unknown. Suboptimal dosages of study treatment could have led to the finding of no differences between treatment groups.

The enalapril study had a low/moderate risk of bias (Silber 2004). There was a low/moderate risk of selection bias, performance bias, and detection bias. For most outcomes there was a low risk of attrition bias, but for some outcomes (the post-hoc analysis of LVESWS, other parameters of cardiac function (SF and SVI), change in quality of life, and risk of adverse events), ITT analysis was not possible or it was unclear if follow-up was complete, leading to a possible risk of attrition bias for these other outcomes. There were no other risks of bias, nor unexpected outcomes or inconsistencies in the data. The phosphocreatine study had a high risk of bias (Chen 2008). We concluded there was a high risk of selection bias, performance bias, and detection bias. There was no sign of attrition bias. There was a risk of reporting bias, and we had concerns about the comparability of the two groups. We found no unexpected outcomes or other inconsistencies in the data.

The external validity of a study indicates how well the results of the study can be generalised to individual patients with anthracycline-induced cardiotoxicity during and after treatment for childhood cancer. Although we did not systematically assess this in this review, we regarded the external validity of the enalapril trial as reasonable (Silber 2004). Participant characteristics were well-defined, and the study population seemed to be a representative sample of childhood cancer survivors who can present with asymptomatic cardiotoxicity during follow-up. However, it should be noted that a large proportion of participants had been treated previously with cardiac radiotherapy. It is not unlikely that the pathophysiology, course, and response to treatment of cardiac dysfunction that is induced by both anthracyclines and radiotherapy is different from cardiac dysfunction caused by anthracyclines only. In addition, other study characteristics could have influenced the effects of treatment. An observational study in adults with anthracycline-induced cardiotoxicity suggested that time between the end of anthracycline treatment and start of heart failure treatment (including at least enalapril) influenced the chance of response to ACE inhibitors, with a longer follow-up time associated with a lower chance of a beneficial effect (Cardinale 2010). Another issue regarding the generalisability of the enalapril trial is that the diagnostic tools to determine cardiotoxicity that were used in this study are not easily used in daily practice. Especially equipment and expertise to determine MCI, LVESWS, and SVI may not be widely available in the follow-up settings of childhood cancer survivors. As previously mentioned, the duration of follow-up precludes extrapolation to follow-up longer than three years. Finally, clear outcome definitions were provided, making it easy to extrapolate the study outcomes to daily practice. The phosphocreatine trial was less well generalisable to daily practice (Chen 2008). Not all participant characteristics were described, including age and gender of the control group, time since leukaemia diagnosis, and information on (previous) cardiotoxic cancer treatment. No clear definitions (that is cutoff values of abnormal diagnostic tests) of cardiotoxicity were provided. No participant had an abnormal echocardiogram, and since most research on anthracycline-induced cardiotoxicity, as well as guidelines on detection of cardiotoxicity, include echocardiographic examination of childhood cancer patients and survivors, we feel that the study group is not very representative with regard to cardiotoxicity (COG 2006; SIGN 2013; Skinner 2005; Steinherz 1992; Van Dalen 2006b). In addition, phosphocreatine is an experimental therapy and not a registered agent at the European Medicines Agency (EMA) or US Food and Drug Administration (FDA). Both the intervention and the control treatments are not common practice in most countries. Treatment duration and outcome assessment of cardiac function 
in this trial were only two weeks, so we only know the immediate effects of the intervention studied and not any long-term benefits or harms. Based on these arguments, we feel that the outcomes of the phosphocreatine trial can hardly be extrapolated to daily clinical practice and care for childhood cancer patients (Chen 2008).

There was no evidence available from RCTs or CCTs for other medical interventions for treating anthracycline-induced symptomatic and asymptomatic cardiotoxicity during and after treatment for childhood cancer (for a complete list of evaluated interventions, see the search strategy in Appendix 1; Appendix 2; Appendix 3).

Please note that in this review RCTs and CCTs were only eligible for inclusion when the participants (previously) had a type of childhood cancer (defined as a diagnosis of cancer at age 18 years or younger). RCTs or CCTs including both children and adults were only eligible for inclusion in this review if the majority of participants were 18 years or younger at cancer diagnosis. It is possible that there are RCTs or CCTs in adults that evaluate the effects of medical interventions on anthracycline-induced cardiotoxicity in cancer patients or survivors. We did not systematically search for trials in adults, but we noted that there was an RCT on enalapril for treating adults with evidence of cardiotoxicity (as indicated by elevated troponin I) after high-dose chemotherapy (which contained anthracycline in most participants) (Cardinale 2006). This trial found that participants treated with enalapril were significantly less likely to experience decline of left ventricular ejection fraction by $10 \%$ compared with untreated participants during oneyear follow-up. There is another ongoing RCT of ranolazine for treatment of diastolic dysfunction in adults who completed standard dose chemotherapy for Hodgkin lymphoma, breast cancer, or colorectal cancer (Minotti 2013). However, this RCT is only aimed at short-term evaluation of cardiac function parameters and biomarkers and will unlikely inform the efficacy of ranolazine in long-term, patient-oriented outcomes such as mortality or cardiac events. There were also some non-controlled observational studies on adults with anthracycline-induced cardiotoxicity (Cardinale 2010; Jensen 1996; Jensen 2002; Noori 2000; Tallaj 2005; Thakur 2014; Vatutin 2001). One of these studies evaluated ACE inhibitor (with or without a beta-blocker) treatment in all study participants (Cardinale 2010). This study was a prospective cohort study with a mean follow-up of 36 months in 201 adults with symptomatic and asymptomatic cardiac dysfunction after anthracycline therapy, who were all treated with at least an ACE inhibitor as soon as cardiac impairment was noted. The study showed a (prespecified) response of cardiac function in $42 \%$, a partial response in $13 \%$, and no response in $45 \%$ of the study group. Responders had fewer cardiac events, and the study found a relationship between the duration of cardiac dysfunction and the probability of response to the therapy. The authors did not report if side effects occurred. It was concluded that beneficial effects of modern heart failure treatment are expected when treatment is started early after the detection of anthracycline-induced cardiotoxicity. It should be noted that it is not always appropriate to extrapolate adult cancer (survivor) studies to childhood cancer (survivor) studies. Other age ranges, pharmacokinetics, pharmacodynamics, as well as comorbidities and co-treatments may influence the effect of interventions for cardiotoxicity as well as the generalisability of studies to the clinical care of childhood cancer patients and survivors. Similarly, RCTs in other childhood populations are also difficult to generalise to childhood cancer patients and survivors. For example, in an RCT of the beta-blocker carvedilol in children with symptomatic heart failure (Shaddy 2007), almost $40 \%$ of the study population had symptomatic heart failure due to congenital heart disease, with often a very different anatomy of the heart.

Even though RCTs provide the highest levels of evidence, observational studies can sometimes be useful when no, or few, RCTs or CCTs are available. A retrospective cohort study described clinical and echocardiographic follow-up of 18 childhood cancer survivors with symptomatic and asymptomatic anthracycline-induced cardiotoxicity from the start of enalapril treatment during a median follow-up of 10 years (Lipshultz 2002). There were no serious side effects during the long-term enalapril treatment in the cohort. The authors found an initial improvement of cardiac function, but a deterioration of cardiac function and clinical parameters after six years of follow-up. However, the study was small, had no control group, and is highly prone to selection, detection, and performance bias. Another retrospective study of childhood cancer survivors treated with anthracyclines compared a group of 34 growth hormone $(\mathrm{GH})$-treated children to a group of 86 children not treated with GH therapy (Lipshultz 2005b). Echocardiographic assessments performed during routine clinical follow-up were reanalysed by an investigator blinded for the intervention. From repeated measurements analyses adjusted for baseline characteristics and non-random missingness of data, the authors' main conclusion was that GH therapy increased left ventricular wall thickness during but not after therapy. It should be noted that among other issues, the retrospective construction of the control group, several confounding factors that were not adjusted for (such as co-treatment with cardiovascular medication), and missing outcome data for a large part of the two groups, put this study at high risk for selection and attrition bias. We can therefore draw no (careful) conclusions from these two observational studies.

We are awaiting the results of the ongoing study (NCT00003070), as well as more information from the two studies for which we could not obtain enough information for inclusion (see Characteristics of studies awaiting classification table). There was no new information about this ongoing study and two studies awaiting classification during the update of the review.

AUTHORS' CONCLUSIONS 


\section{Implications for practice}

We identified one RCT comparing enalapril and placebo in childhood cancer survivors with asymptomatic cardiotoxicity (Silber 2004). Although there is some evidence that enalapril temporarily improves one parameter of cardiac function (LVESWS), the current evidence did not show a statistically significant improvement of other parameters of cardiac function nor of clinical outcomes such as overall survival, mortality due to heart failure, occurrence of clinical heart failure, and quality of life. However, 'no evidence of effect' should not be confused with 'evidence of no effect'. The RCT showed that enalapril treatment is associated with a higher risk of dizziness or hypotension and fatigue. Effects of enalapril on (duration of) hospitalisation, change in NYHA stage of heart failure, and costs were not studied. Also, no evidence was available on the effects of enalapril beyond 2.8 years of follow-up and on treating symptomatic cardiotoxicity. Based on the currently available evidence in childhood cancer survivors with asymptomatic anthracycline-induced cardiac dysfunction, we are not able to provide appropriate recommendations for clinical practice. Clinicians should weigh the potential benefits of enalapril with the known side effects in childhood cancer survivors with asymptomatic anthracycline-induced cardiac dysfunction.

We identified one RCT comparing phosphocreatine and a control treatment of vitamin C, ATP, vitamin E, and oral coenzyme Q10 in childhood leukaemia patients with symptomatic and asymptomatic cardiotoxicity (Chen 2008). Limited data with a high risk of bias and poor generalisability showed no difference of phosphocreatine compared with a control treatment on overall survival, mortality due to heart failure, echocardiographic function, and adverse events. The effect of the intervention on one marker (hsCRP) was unclear, and effects on occurrence of clinical heart failure, (duration) of hospitalisation, change in NYHA stage of heart failure, and costs were not studied. No evidence was available of the effects of phosphocreatine beyond two weeks of treatment or on the effects of phosphocreatine in survivors of childhood cancer with symptomatic or asymptomatic cardiotoxicity. Based on the currently available evidence, we do not recommend the use of phosphocreatine in clinical practice.

We identified no RCTs or CCTs studying other medical interventions for symptomatic or asymptomatic cardiotoxicity in childhood cancer patients or survivors. We can therefore make no conclusions about the effect of other medical interventions in these patients and are unable to provide appropriate recommendations for clinical practice.

\section{Implications for research}

One RCT has studied the effect of enalapril in childhood cancer survivors with asymptomatic anthracycline-induced cardiac dysfunction and found no clear effect on clinical outcomes, possibly due to, among other things, low power of the study (Silber 2004). As there is strong evidence that ACE inhibitors are beneficial for asymptomatic cardiac dysfunction in other populations, we urge the scientific community to start high-quality studies evaluating the effect of enalapril in childhood cancer patients and survivors with symptomatic or asymptomatic anthracycline-induced cardiotoxicity. These studies should preferably be RCTs, within homogenous populations and with long-term follow-up using valid and clinically relevant selection criteria and outcome definitions. Previous treatment with radiotherapy, duration since cancer diagnosis, duration of cardiotoxicity, the age of the patient, the severity of cardiotoxicity, and comorbidity should ideally be taken into account. The number of included participants should be sufficient for the power that is needed for reliable results. In addition, a longterm follow-up study of the enalapril trial (Silber 2004), evaluating the long-term effects of enalapril treatment versus placebo, would be very contributory to the current evidence.

One low-quality RCT has studied the effect of phosphocreatine in childhood leukaemia patients with symptomatic or asymptomatic anthracycline-induced cardiac dysfunction (Chen 2008). Other medical interventions for symptomatic or asymptomatic cardiotoxicity in childhood cancer patients or survivors have not been studied in RCTs or CCTs, even though several potentially beneficial treatment options are available. Evidence on potential treatments for this severe complication is especially needed for symptomatic childhood cancer patients and survivors, therefore, studies with the above-mentioned criteria should also be started evaluating different treatment options in childhood cancer patients and survivors with symptomatic cardiotoxicity.

\section{ACKNOW LEDGEMENTS}

We would like to thank the Editorial Base of Cochrane Childhood Cancer for their advice and support, Oleg Borisenko for translating a Russian article, Robert Shaddy, Charles Canter, and Daphne Hsu for providing additional information about a RCT, Joerg Meerpohl for providing information about one potential study awaiting classification, and Stichting Kinderen Kankervrij (KIKA), the Netherlands for the financial support which made performing this systematic review possible. Huib Caron was a coauthor of the protocol for this systematic review and the original version, and we thank him for his valuable input. The editorial base of Cochrane Childhood Cancer is funded by Kinderen Kankervrij (KIKA). 


\section{R E F E R E N C E S}

\section{References to studies included in this review}

Chen 2008 \{published data only\}

Chen C, Zhou XZ, Fan YM, Qin LJ, Guo HX, Xue HM, et al. Clinical analysis of Sodium phosphocreatine on cardiac toxicity induced by anthracycline antibiotics in acute leukemia children [Unknown original title in Chinese]. Chinese Journal of Cancer Prevention and Treatment 2008;15 (19): 1503-5, 510.

Silber 2004 \{published data only\}

Greevy R, Lu B, Silber JH, Rosenbaum PR. Optimal multivariate matching before randomization. Biostatistics 2004;5(2):263-75.

Greevy R, Silber JH, Cnaan A, Rosenbaum PR. Randomization inference with imperfect compliance in the ACE-inhibitor after anthracycline randomized trial. Journal of the American Statistical Association 2004;99(465):7-15.

Silber JH. Challenges in conducting a pediatric longitudinal prevention study: lessons from the ACE-inhibitor after anthracycline trial. Progress in Pediatric Cardiology 2005;20: 65-70.

Silber JH. The role of afterload reduction in the prevention of late anthracycline cardiomyopathy. Pediatric Blood \& Cancer 2005;44:607-13.

Silber JH, Cnaan A, Clark BJ, Paridon SM, Chin AHJ, Rychik J, et al. Design and baseline characteristics for the ACE inhibitor after anthracycline (AAA) study of cardiac dysfunction in long-term pediatric cancer survivors. American Heart Journal 2001;142:577-85.

* Silber JH, Cnaan A, Clark BJ, Paridon SM, Chin AJ, Rychik J, et al. Enalapril to prevent cardiac function decline in long-term survivors of pediatric cancer exposed to anthracyclines. Journal of Clinical Oncology 2004;22(5): $820-8$.

\section{References to studies excluded from this review}

Garcia 2007 \{published data only\}

Garcia JA, Simvoulidis LF, Salluh JI, Hansen MH, Feres GA, Holanda GS, et al. Levosimendan in acute decompensation of anthracycline-induced cardiotoxicity. International Journal of Cardiology 2007;1 18:406-7.

Ginsberg 2004 \{published data only\} Ginsberg JP, Cnaan A, Zhao H, Clark BJ, Paridon $\mathrm{SM}$, Chin AJ, et al. Using health-related quality of life measures to predict cardiac function in survivors exposed to anthracyclines. Journal of Clinical Oncology 2004;22(15): 3149-55.

Shaddy 2007 \{published data only\}

* Shaddy RE, Boucek MM, Hsu DT, Boucek RJ, Canter CE, Mahony L, et al. Carvedilol for children and adolescents with heart failure: a randomized controlled trial. JAMA 2007;298(10):1171-9.

Shaddy RE, Curtin EL, Sower B, Tani LY, Burr J, LaSalle B, et al. The pediatric randomized carvedilol trial in children with heart failure: rationale and design. American Heart Journal 2002;144(3):383-9.

Tallaj 2005 \{published data only\}

Tallaj JA, Franco V, Rayburn BK, Pinderski L, Benza RL, Pamboukian S, et al. Response of doxorubicin-induced cardiomyopathy to the current management strategy of heart failure. Journal of Heart and Lung Transplantation 2005;24(12):2196-201.

Vatutin 2001 \{published data only\} Vatutin NT, Keting EV, Kalinkina NV, Dunaeva OA, Kardashevskaia LI. Effect of propranolol in silent myocardial ischemia induced by anthracyclines [Vliianie propranolola na bezbolevuiu ishemiiu miokarda, vyzvannuiu antratsiklinami]. Likars'ka sprava 2001;1:106-9.

\section{References to studies awaiting assessment}

Mandric 2008 \{published data only\} Mandric CG, Miron I, Dimitriu AG, Baghiu D, Dimitriu L, Miron OT. The utility of enalapril treatment in anthracyclines-induced cardiac injury in children with malignancies - preliminary study. Proceedings of the 40th Annual Conference of International Society of Paediatric Oncology (SIOP); 2008 Oct 2-6; Berlin, Germany. 2008: Abstract L.030, print: 207-8.

Mandric 2009 \{published data only\}

Mandric CG, Miron I, Dimitriu AG, Dumitriu IL. Cardiac biomarkers in early detection of cardiotoxicity anthracycline-induced in children. Proceedings of the 41st Annual Conference of International Society of Paediatric Oncology (SIOP); 2009 Oct 5-9; Sao Paulo, Brazil. 2009: Abstract PQ.020, Pediatric Blood \& Cancer 2009;53:858.

\section{References to ongoing studies}

\section{NCT00003070 \{published data only\}}

NCT00003070. Afterload reduction therapy for late anthracycline cardiotoxicity: a Pediatric Oncology Group Cancer Control Study. http://apps.who.int/trialsearch/ Trial2.aspx?TrialID=NCT00003070. Accessed on 29 September 2015.

\section{Additional references}

Abdulla 2006

Abdulla J, Pogue J, Abildstrom SZ, Kober L, Christensen E, Pfeffer MA, et al. Effect of angiotensin-converting enzyme inhibition on functional class in patients with left ventricular systolic dysfunction - a meta-analysis. European Journal of Heart Failure 2006;8(1):90-6.

Armenian 2014 Armenian SH, Gelehrter SK, Vase T, Venkatramani R, Landier W, Wilson KD, et al. Screening for cardiac dysfunction in anthracycline-exposed childhood cancer survivors. Clinical Cancer Research 2014;20(24):6314-23.

Medical interventions for treating anthracycline-induced symptomatic and asymptomatic cardiotoxicity during and after treatment for 


\section{Armenian 2015}

Armenian SH, Hudson MM, Mulder RL, Chen MH, Constine LS, Dwyer M, et al. Recommendations for cardiomyopathy surveillance for survivors of childhood cancer: a report from the International Late Effects of Childhood Cancer Guideline Harmonization Group. The Lancet Oncology 2015;16(3):e123-36.

\section{Cardinale 2006}

Cardinale D, Colombo A, Sandri MT, Lamantia G, Colombo N, Civelli M, et al. Prevention of high-dose chemotherapy-induced cardiotoxicity in high-risk patients by angiotensin-converting enzyme inhibition. Circulation 2006;114(23):2474-81.

Cardinale 2010

Cardinale D, Colombo A, Lamantia G, Colombo N, Civelli M, De Giacomi G, et al. Anthracycline-induced cardiomyopathy: clinical relevance and response to pharmacologic therapy. Journal of the American College of Cardiology 2010;55(3):213-20.

\section{CIBIS-II 1999}

The Cardiac Insufficiency Bisoprolol Study II (CIBIS-II): a randomised trial. The Lancet 1999;353(9146):9-13.

\section{COG 2006}

Children's Oncology Group. Long-term follow-up guidelines for survivors of childhood, adolescent and young adult cancers, version 3.0. Arcadia, CA. 2006. Available at: www.survivorshipguidelines.org.

\section{Cohn 2001}

Cohn JN, Tognoni G. A randomized trial of the angiotensinreceptor blocker valsartan in chronic heart failure. The New England Journal of Medicine 2001;345(23):1667-75.

\section{Colucci 2007}

Colucci WS, Kolias TJ, Adams KF, Armstrong WF, Ghali JK, Gottlieb SS, et al. Metoprolol reverses left ventricular remodeling in patients with asymptomatic systolic dysfunction: the REversal of VEntricular Remodeling with Toprol-XL (REVERT) trial. Circulation 2007;116(1): $49-56$.

\section{Exner 1999}

Exner DV, Dries DL, Waclawiw MA, Shelton B, Domanski MJ. Beta-adrenergic blocking agent use and mortality in patients with asymptomatic and symptomatic left ventricular systolic dysfunction: a post hoc analysis of the Studies of Left Ventricular Dysfunction. Journal of the American College of Cardiology 1999;33(4):916-23.

Foody 2002

Foody JM, Farrell MH, Krumholz HM. Beta-blocker therapy in heart failure: scientific review. JAMA 2002;287 (7):883-9.

Ganame 2007

Ganame J, Claus P, Uyttebroeck A, Renard M, D'hooge J, Bijnens B, et al. Myocardial dysfunction late after low-dose anthracycline treatment in asymptomatic pediatric patients. Journal of the American Society of Echocardiography 2007;20 (12):1351-8.

\section{Garg 1995}

Garg R, Yusuf S. Overview of randomized trials of angiotensin-converting enzyme inhibitors on mortality and morbidity in patients with heart failure. Collaborative Group on ACE Inhibitor Trials. JAMA 1995;273(18): 1450-6.

\section{Glick 1995}

Glick H, Cook J, Kinosian B, Pitt B, Bourassa MG, Pouleur $\mathrm{H}$, et al. Costs and effects of enalapril therapy in patients with symptomatic heart failure: an economic analysis of the Studies of Left Ventricular Dysfunction (SOLVD) Treatment Trial. Journal of Cardiac Failure 1995;1(5): 371-80.

\section{Granger 2003}

Granger CB, McMurray JJ, Yusuf S, Held P, Michelson EL, Olofsson B, et al. Effects of candesartan in patients with chronic heart failure and reduced left-ventricular systolic function intolerant to angiotensin-converting-enzyme inhibitors: the CHARM-Alternative trial. The Lancet 2003; 362(9386):772-6.

\section{Higgins 2008}

Higgins JPT, Green S (editors). Cochrane Handbook for Systematic Reviews of Interventions Version 5.0.0 (updated February 2008). The Cochrane Collaboration, 2008. Available from www.cochrane-handbook.org.

\section{Jensen 1996}

Jensen BV, Nielsen SL, Skovsgaard T. Treatment with angiotensin-converting-enzyme inhibitor for epirubicininduced dilated cardiomyopathy. The Lancet 1996;347 (8997):297-9.

\section{Jensen 2002}

Jensen BV, Skovsgaard T, Nielsen SL. Functional monitoring of anthracycline cardiotoxicity: a prospective, blinded, long-term observational study of outcome in 120 patients. Annals of Oncology 2002;13(5):699-709.

Jong 2003

Jong P, Yusuf S, Rousseau MF, Ahn SA, Bangdiwala SI. Effect of enalapril on 12-year survival and life expectancy in patients with left ventricular systolic dysfunction: a followup study. The Lancet 2003;361 (9372):1843-8.

Kay 2001

Kay JD, Colan SD, Graham TP Jr. Congestive heart failure in pediatric patients. American Heart Journal 2001;142(5): 923-8.

\section{Kremer 2002}

Kremer LC, van Der Pal HJ, Offringa M, van Dalen EC, Voute PA. Frequency and risk factors of subclinical cardiotoxicity after anthracycline therapy in children: a systematic review. Annals of Oncology 2002;13(6):819-29.

\section{Lefrak 1973}

Lefrak EA, Pitha J, Rosenheim S, Gottlieb JA. A clinicopathologic analysis of adriamycin cardiotoxicity. Cancer 1973;32(2):302-14.

Lipshultz 1991

Lipshultz SE, Colan SD, Gelber RD, Perez-Atayde AR, Sallan SE, Sanders SP. Late cardiac effects of doxorubicin 
therapy for acute lymphoblastic leukemia in childhood. The New England Journal of Medicine 1991;324(12):808-15.

\section{Lipshultz 2002}

Lipshultz SE, Lipsitz SR, Sallan SE, Simbre VC, Shaikh SL, Mone SM, et al. Long-term enalapril therapy for left ventricular dysfunction in doxorubicin-treated survivors of childhood cancer. Journal of Clinical Oncology 2002;20(23): 4517-22.

Lipshultz 2005a

Lipshultz SE, Lipsitz SR, Sallan SE, Dalton VM, Mone SM, Gelber RD, et al. Chronic progressive cardiac dysfunction years after doxorubicin therapy for childhood acute lymphoblastic leukemia. Journal of Clinical Oncology 2005; 23(12):2629-36.

Lipshultz 2005b

Lipshultz SE, Vlach SA, Lipsitz SR, Sallan SE, Schwartz ML, Colan SD. Cardiac changes associated with growth hormone therapy among children treated with anthracyclines.

Pediatrics 2005;115:1613-22.

\section{Maggioni 2002}

Maggioni AP, Anand I, Gottlieb SO, Latini R, Tognoni G, Cohn JN. Effects of valsartan on morbidity and mortality in patients with heart failure not receiving angiotensinconverting enzyme inhibitors. Journal of the American College of Cardiology 2002;40(8):1414-21.

\section{McMurray 2003}

McMurray JJ, Ostergren J, Swedberg K, Granger CB, Held P, Michelson EL, et al. Effects of candesartan in patients with chronic heart failure and reduced left-ventricular systolic function taking angiotensin-converting-enzyme inhibitors: the CHARM-Added trial. The Lancet 2003;362 (9386):767-71

\section{Minotti 2013}

Minotti G. Pharmacology at work for cardio-oncology: ranolazine to treat early cardiotoxicity induced by antitumor drugs. Journal of Pharmacology and Experimental Therapeutics 2013;346(3):343-9.

\section{Module CCG}

Kremer LCM, van Dalen EC, Moher D, Caron HN. Childhood Cancer Group. About the Cochrane Collaboration (Cochrane Review Groups CRGs) 2008, Issue 4. Art. No.: CHILDCA.

Mulrooney 2009

Mulrooney DA, Yeazel MW, Kawashima T, Mertens AC, Mitby P, Stovall M, et al. Cardiac outcomes in a cohort of adult survivors of childhood and adolescent cancer: retrospective analysis of the Childhood Cancer Survivor Study cohort. BMJ 2009;339:b4606.

Noori 2000

Noori A, Lindenfeld J, Wolfel E, Ferguson D, Bristow MR, Lowes BD. Beta-blockade in adriamycin-induced cardiomyopathy. Journal of Cardiac Failure 2000;6(2): $115-9$.

\section{NYHA 1994}

The Criteria Committee of the New York Heart Association. Nomenclature and Criteria for Diagnosis of Diseases of the Heart and Great Vessels. 9th Edition. Boston: Little, Brown \& Co, 1994.

\section{Packer 1996a}

Packer M, Bristow MR, Cohn JN, Colucci WS, Fowler MB, Gilbert EM, et al. The effect of carvedilol on morbidity and mortality in patients with chronic heart failure. U.S. Carvedilol Heart Failure Study Group. The New England Journal of Medicine 1996;334(21):1349-55.

\section{Packer 1996b}

Packer M, Colucci WS, Sackner-Bernstein JD, Liang CS, Goldscher DA, Freeman I, et al. Double-blind, placebocontrolled study of the effects of carvedilol in patients with moderate to severe heart failure. The PRECISE Trial. Prospective Randomized Evaluation of Carvedilol on Symptoms and Exercise. Circulation 1996;94(11):2793-9.

\section{Parmar 1998}

Parmar MK, Torri V, Stewart L. Extracting summary statistics to perform meta-analyses of the published literature for survival endpoints. Statistics in Medicine 1998; 17:2815-34.

RevMan 2014 [Computer program]

The Nordic Cochrane Centre. The Cochrane Collaboration. Review Manager (RevMan). Version 5.3. Copenhagen: The Nordic Cochrane Centre. The Cochrane Collaboration, 2014.

\section{Rogers 1994}

Rogers WJ, Johnstone DE, Yusuf S, Weiner DH, Gallagher P, Bittner VA, et al. Quality of life among 5,025 patients with left ventricular dysfunction randomized between placebo and enalapril: the Studies of Left Ventricular Dysfunction. Journal of the American College of Cardiology 1994;23(2):393-400.

\section{Sieswerda 2012}

Sieswerda E, Postma A, van Dalen EC, van der Pal HJ, Tissing WJ, Rammeloo LA, et al. The Dutch Childhood Oncology Group guideline for follow-up of asymptomatic cardiac dysfunction in childhood cancer survivors. Annals of Oncology 2012;23(8):2191-8.

\section{SIGN 2013}

Scottish Intercollegiate Guideline Network (SIGN). Longterm follow up care of survivors of childhood cancer. 2013. SIGN publication no. 132: available at: http:// www.sign.ac.uk/pdf/sign132.pdf. Accessed on 8 August 2016.

\section{Skinner 2005}

Skinner R, Wallace WH, Levitt G. Therapy based long term follow up: A practice statement (second edition). United Kingdom Children's Cancer Study Group, Late Effects Group 2005. Available at: http://www.uhb.nhs.uk/Downloads/pdf/ CancerPbTherapyBasedLongTermFollowUp.pdf. Accessed on 8 August 2016.

Medical interventions for treating anthracycline-induced symptomatic and asymptomatic cardiotoxicity during and after treatment for 


\section{SOLVD 1991}

Effect of enalapril on survival in patients with reduced left ventricular ejection fractions and congestive heart failure. The SOLVD Investigators. The New England Journal of Medicine 1991;325(5):293-302.

\section{SOLVD 1992}

Effect of enalapril on mortality and the development of heart failure in asymptomatic patients with reduced left ventricular ejection fractions. The SOLVD Investigators. The New England Journal of Medicine 1992;327(10): 685-91.

\section{Sorensen 2003}

Sorensen K, Levitt GA, Bull C, Dorup I, Sullivan ID. Late anthracycline cardiotoxicity after childhood cancer: a prospective longitudinal study. Cancer 2003;97(8):1991-8.

Steinherz 1992

Steinherz LJ, Graham T, Hurwitz R, Sondheimer HM, Schwartz RG, Shaffer EM, et al. Guidelines for cardiac monitoring of children during and after anthracycline therapy: report of the cardiology committee of the Children's Cancer Study Group. Pediatrics 1992;89:942-9.

\section{Steinherz 1995}

Steinherz LJ, Steinherz PG, Tan C. Cardiac failure and dysrhythmias 6-19 years after anthracycline therapy: a series of 15 patients. Medical and Pediatric Oncology 1995;24(6): $352-61$.

Thakur 2014

Thakur A, Witteles RM. Cancer therapy-induced left ventricular dysfunction: interventions and prognosis. Journal of Cardiac Failure 2014;20(3):155-8.

Van Dalen 2003

Van Dalen EC, van Der Pal HJ, van Den Bos C, Caron HN, Kremer LC. Treatment for asymptomatic anthracyclineinduced cardiac dysfunction in childhood cancer survivors: the need for evidence. Journal of Clinical Oncology 2003;21 (17):3377-8.

\section{Van Dalen 2006a}

Van Dalen EC, van Der Pal HJ, Kok WE, Caron HN, Kremer LC. Clinical heart failure in a cohort of children treated with anthracyclines: a long-term follow-up study. European Journal of Cancer 2006;42(18):3191-8.

\section{Van Dalen 2006b}

Van Dalen EC, van den Brug M, Caron HN, Kremer LC. Anthracycline-induced cardiotoxicity: Comparison of recommendations for monitoring cardiac function during therapy in paediatric oncology trials. European Journal of Cancer 2006;42:3199-205.
Van Dalen 2014

Van Dalen EC, Raphaël MF, Caron HN, Kremer LC. Treatment including anthracyclines versus treatment not including anthracyclines for childhood cancer. Cochrane Database of Systematic Reviews 2014, Issue 9. [DOI: 10.1002/14651858.CD006647.pub4]

\section{Van der Pal 2012}

Van der Pal HJ, van Dalen EC, van Delden E, van Dijk IW, Kok WE, Geskus RB, et al. High risk of symptomatic cardiac events in childhood cancer survivors. Journal of Clinical Oncology 2012;30(13):1429-37.

\section{Von Hoff 1977}

Von Hoff DD, Rozencweig M, Layard M, Slavik M, Muggia FM. Daunomycin-induced cardiotoxicity in children and adults. A review of 110 cases. American Journal of Medicine 1977;62(2):200-8.

\section{Waagstein 1993}

Waagstein F, Bristow MR, Swedberg K, Camerini F, Fowler $\mathrm{MB}$, Silver MA, et al. Beneficial effects of metoprolol in idiopathic dilated cardiomyopathy. Metoprolol in Dilated Cardiomyopathy (MDC) Trial Study Group. The Lancet 1993;342(8885):1441-6

Wang 2003

Wang TJ, Evans JC, Benjamin EJ, Levy D, LeRoy EC, Vasan RS. Natural history of asymptomatic left ventricular systolic dysfunction in the community. Circulation 2003; 108(8): $977-82$.

\section{Wilson 1968}

Wilson JMG, Jungner G. Principles and practice of screening for disease. WHO Chronicle 1968;22(11):473.

\section{References to other published versions of this review}

\section{Sieswerda 2009}

Sieswerda E, van Dalen EC, Postma A, Caron HN, Kremer LC. Medical interventions for treating anthracyclineinduced symptomatic and asymptomatic cardiotoxicity during and after treatment for childhood cancer. Cochrane Database of Systematic Reviews 2009, Issue 4. [DOI: 10.1002/14651858.CD008011]

\section{Sieswerda 2011}

Sieswerda E, van Dalen EC, Postma A, Cheuk DKL, Caron $\mathrm{HN}$, Kremer LCM. Medical interventions for treating anthracycline-induced symptomatic and asymptomatic cardiotoxicity during and after treatment for childhood cancer. Cochrane Database of Systematic Reviews 2011, Issue 9. [DOI: 10.1002/14651858.CD008011.pub2]

* Indicates the major publication for the study 


\section{CHARACTERISTICS OF STUDIES}

\section{Characteristics of included studies [ordered by study ID]}

\section{Chen 2008}

\begin{tabular}{|c|c|}
\hline Methods & RCT using simple random allocation to intervention and control groups \\
\hline Participants & $\begin{array}{l}68 \text { childhood cancer patients, receiving phosphocreatine or control treatment of a com- } \\
\text { bination of vitamin C, ATP, vitamin E, and coenzyme Q10 } \\
\text { Included participants had anthracycline-related cardiotoxicity based on cardiac enzymes } \\
\text { (CK, CK-MB, LDH1, alphaHBDH, troponin I, hsCRP), ECG and/or echocardiogram } \\
\text { Median (range) age of the phosphocreatine group was } 5 \text { ( } 1 \text { to } 15 \text { ) years; } 15 \text { of } 35 \text { were } \\
\text { males. Age and gender of the control group were not mentioned. Median time since } \\
\text { cancer diagnosis was not mentioned. Participants had a diagnosis of acute lymphatic } \\
\text { leukaemia or acute myeloid leukaemia } \\
\text { For both groups information on (previous) cardiotoxic cancer treatment (cumulative } \\
\text { anthracycline dose, cardiac radiotherapy and dose, and cardioprotective interventions) } \\
\text { was not mentioned. Other cardiovascular comorbidities and treatments were also not } \\
\text { mentioned } \\
\text { At the start of the study, distribution of abnormalities in cardiac symptoms and signs } \\
\text { in the treatment group ( } \mathrm{n}=35 \text { ) was: cardiac symptoms } 18 \text {, abnormal cardiac enzymes } \\
\text { 28, abnormal troponin I } 7 \text {, abnormal ECG } 20 \text {, and abnormal echocardiogram } 0 \text {. Mean } \\
\text { (SD) hsCRP in the treatment group was } 8.79 \text { (1.36) mg/L. For the control group (n }= \\
33 \text { ) this distribution was: cardiac symptoms } 16 \text {, abnormal cardiac enzymes } 25 \text {, abnormal } \\
\text { troponin I } 7 \text {, abnormal ECG 18, and abnormal echocardiogram } 0 \text {. Mean (SD) hsCRP } \\
\text { in the control group was } 7.88 \text { (2.08) mg/L. Time since diagnosis of cardiotoxicity was } \\
\text { not mentioned }\end{array}$ \\
\hline
\end{tabular}

Interventions

Phosphocreatine $1 \mathrm{~g}$ intravenously over 30 to 40 minutes once to twice per day $(\mathrm{n}=35)$ or a combination treatment of vitamin C $150 \mathrm{mg} / \mathrm{kg}$ and ATP $20 \mathrm{mg}$ into $5 \%$ glucose $100 \mathrm{ml}$ intravenously once per day, oral vitamin E $50 \mathrm{mg}$ once per day, and oral coenzyme Q10 (ubidecarenone) $10 \mathrm{mg} 3$ times per day. All treatment durations were 14 days

Outcomes

Overall survival.

Mortality due to heart failure (no definitions provided).

Occurrence of adverse events (no definition provided).

Change in cardiac function (normal/abnormal echocardiography, change in hsCRP, normal/abnormal ECG, normal/abnormal cardiac enzymes (CK, CK-MB, LDH1, alphaHBDH, troponin I, and hsCRP), postintervention levels of CK, CK-MB, LDH1, alphaHBDH, and troponin I. No definitions were provided)

Notes

The abstract (in English) mentions "retrospectively assessed". However, we think the study is an RCT, because there is a statement in the methods section (in Chinese) that "all patients have entered the clinical trial with simple random allocation to treatment and control groups."

Duration of follow-up was not mentioned, but it seems that it was 15 days for the assessment of cardiac function, since that was done at the beginning and one day after the intervention. For clinical outcomes this was unclear. There was no loss to follow-up

Medical interventions for treating anthracycline-induced symptomatic and asymptomatic cardiotoxicity during and after treatment for 
Chen 2008 (Continued)

\section{Risk of bias}

\begin{tabular}{|c|c|c|}
\hline Bias & Authors' judgement & Support for judgement \\
\hline Blinding of participants? & High risk & $\begin{array}{l}\text { Blinding of participants was not mentioned } \\
\text { but seemed inadequate or very unlikely } \\
\text { since the intervention and control treat- } \\
\text { ment had different routes of administration }\end{array}$ \\
\hline Blinding of personnel? & High risk & $\begin{array}{l}\text { Blinding of personnel was not mentioned } \\
\text { but seemed inadequate or very unlikely } \\
\text { since the intervention and control treat- } \\
\text { ment had different routes of administration }\end{array}$ \\
\hline $\begin{array}{l}\text { Blinding of outcome assessors? } \\
\text { Mortality due to heart failure }\end{array}$ & Unclear risk & $\begin{array}{l}\text { Blinding of outcome assessors was not } \\
\text { mentioned }\end{array}$ \\
\hline $\begin{array}{l}\text { Blinding of outcome assessors? } \\
\text { Occurrence of adverse events and tolerabil- } \\
\text { ity (as defined by authors) }\end{array}$ & Unclear risk & $\begin{array}{l}\text { Blinding of outcome assessors was not } \\
\text { mentioned }\end{array}$ \\
\hline
\end{tabular}

\begin{tabular}{|c|c|c|}
\hline $\begin{array}{l}\text { Blinding of outcome assessors? } \\
\text { Change in cardiac function measured by a } \\
\text { diagnostic test (as defined by authors) }\end{array}$ & Unclear risk & $\begin{array}{l}\text { Blinding of outcome assessors was not } \\
\text { mentioned }\end{array}$ \\
\hline
\end{tabular}

\begin{tabular}{|c|c|c|}
\hline $\begin{array}{l}\text { Completeness of follow-up } \\
\text { Overall survival }\end{array}$ & Low risk & $\begin{array}{l}\text { Outcome could be abstracted for all partic- } \\
\text { ipants }\end{array}$ \\
\hline
\end{tabular}

Completeness of follow-up Low risk

Mortality due to heart failure
Outcome could be abstracted for all participants

Completeness of follow-up Low risk

Outcome was provided for all participants

Occurrence of adverse events and tolerabil-

ity (as defined by authors)

Completeness of follow-up

Change in cardiac function measured by a

diagnostic test (as defined by authors)
Low risk

Completeness of follow-up

Change in cardiac function measured by a

diagnostic test (as defined by authors)
Low risk \begin{tabular}{l}
\hline Intention-to-treat-analysis? \\
Overall survival
\end{tabular}

Intention-to-treat-analysis?

Mortality due to heart failure
Low risk

tow risk
For echocardiography (normal/abnormal) change in outcome was provided for all participants

For 1 biomarker (hsCRP) change in outcome was provided for all participants
Allocation was provided for the reported outcome

Allocation was provided for the reported outcome 


\section{Chen 2008 (Continued)}

\begin{tabular}{|c|c|c|}
\hline $\begin{array}{l}\text { Intention-to-treat-analysis? } \\
\text { Occurrence of adverse events and tolerabil- } \\
\text { ity (as defined by authors) }\end{array}$ & Low risk & $\begin{array}{l}\text { Allocation was provided for the reported } \\
\text { outcome }\end{array}$ \\
\hline $\begin{array}{l}\text { Intention-to-treat-analysis? } \\
\text { Change in cardiac function measured by a } \\
\text { diagnostic test (as defined by authors) }\end{array}$ & Low risk & $\begin{array}{l}\text { For echocardiography (normal/abnormal) } \\
\text { treatment allocation was provided }\end{array}$ \\
\hline $\begin{array}{l}\text { Intention-to-treat-analysis? } \\
\text { Change in cardiac function measured by a } \\
\text { diagnostic test (as defined by authors) }\end{array}$ & Low risk & $\begin{array}{l}\text { For the biomarker (hsCRP) treatment allo- } \\
\text { cation was provided }\end{array}$ \\
\hline Free of selective reporting? & Unclear risk & $\begin{array}{l}\text { We found no published protocol in which } \\
\text { the reported outcomes and analyses were } \\
\text { prespecified }\end{array}$ \\
\hline Free of other bias? & High risk & $\begin{array}{l}\text { The baseline characteristics were not fully } \\
\text { described. For example, there was no data } \\
\text { about the gender and age distribution of the } \\
\text { control group. We do not know what type } \\
\text { of anthracycline and what doses of medi- } \\
\text { cations were used in each group, and we } \\
\text { have no information on whether radiation } \\
\text { therapy was given. We are therefore uncer- } \\
\text { tain whether the intervention and control } \\
\text { groups were comparable/similar at baseline } \\
\text { We are uncertain whether co-interventions } \\
\text { were different between the intervention } \\
\text { and control groups }\end{array}$ \\
\hline Random sequence generation? & Unclear risk & No description of sequence generation \\
\hline Allocation concealment? & Unclear risk & No description of allocation concealment \\
\hline
\end{tabular}

Silber 2004

Methods

ACE inhibitor After Anthracycline (AAA) trial. Double-blinded RCT. Randomisations were performed using random permuted blocks (random size between 2 and 8) with equal allocation to each treatment (stratified according to the variables age at treatment (under 3 years old versus 3 years or older), total cumulative anthracycline dose (under $300 \mathrm{mg} / \mathrm{m}^{2}$ versus $300 \mathrm{mg} / \mathrm{m}^{2}$ or higher), and time from diagnosis (less than 10 years versus 10 years or more))

Participants

135 childhood cancer survivors (aged 8.3 to 30.6 years, 78 males) with asymptomatic decline of cardiac function at some time after anthracycline exposure, detected with echocardiography, resting or exercise GNA, MCI at peak exercise, and/or resting ECG Median (range) time since cancer diagnosis 9 (4.2 to 22.3) years in the enalapril group and 9.6 ( 4.3 to 25.8 ) years in the placebo group. Participants had been treated for various

Medical interventions for treating anthracycline-induced symptomatic and asymptomatic cardiotoxicity during and after treatment for 22 childhood cancer (Review)

Copyright $\odot 2016$ The Cochrane Collaboration. Published by John Wiley \& Sons, Ltd. 
types of cancer diagnosis at a median (range) age of 7.2 (3 to 21.8) years in the enalapril group and 8.2 (0.3 to 10.3 ) years in the placebo group. Median (range) age at study entry was 17 (8.3 to 31.5$)$ years in enalapril group and 18.9 (8.1 to 30.6$)$ years in placebo group

Previous anthracycline treatment with median (range) cumulative anthracycline dose 305 (75 to 396$) \mathrm{mg} / \mathrm{m}^{2}$ in enalapril group and 300 (75 to 738$) \mathrm{mg} / \mathrm{m}^{2}$ in placebo group (types of anthracyclines not mentioned). Previous cardiac radiotherapy in enalapril group: 26 (38\%), unknown in $1(1.4 \%)$. In placebo group: $23(35 \%)$, unknown in 0 $(0 \%)$. Other previous potential cardiotoxic treatment or cardioprotective interventions not mentioned. Total radiotherapy dose, other cardiovascular comorbidities, and treatments were not mentioned. 1 participant in enalapril group required a growth hormone supplement and 1 participant in placebo group required a testosterone supplement.

At the start of the study, 111 participants had echocardiographic abnormalities (based on SF, LVESWS, and/or SVI) and/or abnormalities during resting or exercise GNA (based on EF). Of the remaining 24 participants, 7 had (only) abnormalities on cycle ergometry (based on MCI), and 17 had any of the abnormalities (possibly including an abnormal QTc interval on ECG) before study entry. Mean (SD) cardiac function in enalapril group was: $\mathrm{MCI}\left(\mathrm{L} / \mathrm{min} / \mathrm{m}^{2}\right): 8.39$ (2.66) (68 participants), LVESWS $\left(\mathrm{g} / \mathrm{cm}^{2}\right): 73.2$ (19.0) (69 participants), EF (\%): 59.1 (7.4) (69 participants), SF (\%): 30.7 (4.9) (69 participants) , QTc (ms): 418 (23.4) (69 participants). Mean (SD) cardiac function in placebo group was: $\mathrm{MCI}\left(\mathrm{L} / \mathrm{min} / \mathrm{m}^{2}\right): 8.24$ (2.57) (65 participants), LVESWS $\left(\mathrm{g} / \mathrm{cm}^{2}\right): 68.4(20.4)(66$ participants), EF (\%): 58.3 (7.1) (64 participants), SF (\%): 30.6 (3.9) (66 participants), QTc (ms): 411 (17.6) (66 participants). Time since diagnosis of cardiotoxicity was not mentioned medication was as follows: at start $0.05 \mathrm{mg} / \mathrm{kg} /$ day, escalation after 14 days to $0.10 \mathrm{mg} /$ $\mathrm{kg} /$ day, and escalation at 3-months visit to $0.15 \mathrm{mg} / \mathrm{kg} / \mathrm{day}$ if no side effects occurred

Outcomes

Overall survival.

Mortality due to heart failure (no definitions provided).

Development of clinical heart failure (defined as a clinically significant decline in cardiac performance: documented acute congestive heart failure, SF decline 20\% (and below $28 \%$ ) from baseline in 2 measures or MCI decline by 30\% (and 2 SD below the mean) from baseline in 2 measures)

Occurrence of adverse events (no definition provided).

Change in cardiac function (Primary outcome: rate of decline over time of MCI. Secondary outcome: rate of increase over time in LVESWS. Other outcomes: first-year reduction in LVESWS (post-hoc and ITT analysis), \% change in SF and change in SVI over time)

Quality of life: based on the Short-Form 36 General Health Survey (age above 14 years) or the Childhood Health Questionnaire-85 (age equal to or younger than 14 years). No definition for an abnormal outcome was provided

Median (range) follow-up time was 2.80 years ( 2 weeks to 6.1 years). Loss to follow-up was not mentioned

Since the authors did not present dichotomous outcomes, we were not able to define RRs for the outcome change in cardiac function; we have therefore described the outcomes 
Silber 2004 (Continued)

as presented in the original study

\section{Risk of bias}

\begin{tabular}{|c|c|c|}
\hline Bias & Authors' judgement & Support for judgement \\
\hline Blinding of participants? & Low risk & $\begin{array}{l}\text { Participants were effectively blinded to the } \\
\text { intervention }\end{array}$ \\
\hline
\end{tabular}

Blinding of personnel? $\quad$ Low risk

Investigators were blinded to the intervention. Based on this statement and the effective blinding of participants, we judged that the personnel were effectively blinded

Blinding of outcome assessors? Low risk

Mortality due to heart failure

Investigators were blinded to the intervention. Based on this statement and the effective blinding of participants, we judged that the outcome assessors were effectively blinded

Blinding of outcome assessors? Low risk

Development of clinical heart failure (as de-

fined by authors)
Investigators were blinded to the intervention. Based on this statement and the effective blinding of participants, we judged that the outcome assessors were effectively blinded

Blinding of outcome assessors? Low risk Occurrence of adverse events and tolerability (as defined by authors)
Investigators were blinded to the intervention. Based on this statement and the effective blinding of participants, we judged that the outcome assessors were effectively blinded

Investigators were blinded to the intervention. Based on this statement and the effective blinding of participants, we judged that the outcome assessors were effectively blinded

Investigators were blinded to the intervention. Based on this statement and the effective blinding of participants, we judged that the outcome assessors were effectively blinded

Outcome could be abstracted from all participants

Outcome could be abstracted from all participants 


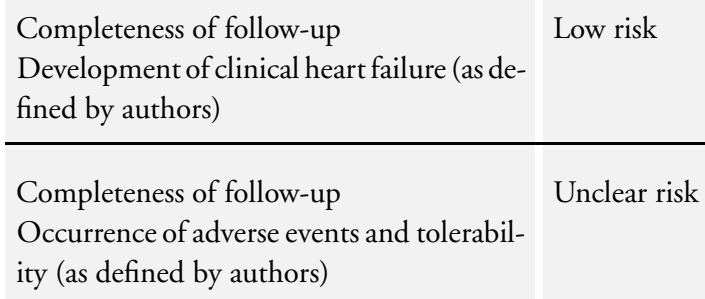

Change in cardiac function measured by a diagnostic test (as defined by authors)

Completeness of follow-up
Change in cardiac function measured by a
diagnostic test (as defined by authors)

Completeness of follow-up

Change in cardiac function measured by a

diagnostic test (as defined by authors)

Completeness of follow-up
Change in quality of life (as defined by au-
thors)

$\begin{array}{ll}\text { Intention-to-treat-analysis? } & \text { Low risk }\end{array}$

Overall survival

Low risk

Unclear risk

Unclear risk

Low risk

Intention-to-treat-analysis?

Mortality due to heart failure

Intention-to-treat-analysis? Low risk

Development of clinical heart failure (as de-

fined by authors)

Intention-to-treat-analysis?

Occurrence of adverse events and tolerabil-

ity (as defined by authors)
Low risk

Low risk outcome
For MCI, any follow-up measurement was done in $83 \%$ of the participants. Completeness of follow-up at the end of the study was not mentioned

For LVESWS, follow-up was $93 \%$ in the first year. Follow-up after the first year was not mentioned

For other outcomes of cardiac function (SF and SVI), completeness of follow-up was not mentioned

Completeness of follow-up not mentioned
Intention-to-treat-analysis?

Low risk

Change in cardiac function measured by a

diagnostic test (as defined by authors)
High risk

Change in cardiac function measured by a

diagnostic test (as defined by authors)
Allocation was provided for the reported outcome

Allocation was provided for the reported outcome

Allocation was provided for the reported outcome

Allocation was provided for the reported

For change in MCI and LVESWS, study authors performed intention-to-treat-analyses

For the extra post-hoc analysis of change in LVESWS (piecewise model), study authors performed a per-protocol analysis 


\begin{tabular}{|c|c|c|}
\hline $\begin{array}{l}\text { Intention-to-treat-analysis? } \\
\text { Change in cardiac function measured by a } \\
\text { diagnostic test (as defined by authors) }\end{array}$ & Unclear risk & $\begin{array}{l}\text { For other outcomes of cardiac function (SF } \\
\text { and SVI), it was not stated if intention-to- } \\
\text { treat-analyses were performed }\end{array}$ \\
\hline $\begin{array}{l}\text { Intention-to-treat-analysis? } \\
\text { Change in quality of life (as defined by au- } \\
\text { thors) }\end{array}$ & Low risk & $\begin{array}{l}\text { Allocation was provided for the reported } \\
\text { outcome }\end{array}$ \\
\hline Free of selective reporting? & Low risk & $\begin{array}{l}\text { There was a published protocol in which } \\
\text { the reported outcomes and analyses were } \\
\text { prespecified. All outcomes were reported } \\
\text { and the analyses were done in the final } \\
\text { report. The authors clearly explained that } \\
\text { they had performed some additional anal- } \\
\text { yses based on exploration of the data }\end{array}$ \\
\hline Free of other bias? & Low risk & No other bias was identified \\
\hline Random sequence generation? & Low risk & $\begin{array}{l}\text { Randomisations were performed using ran- } \\
\text { dom permuted blocks (random size be- } \\
\text { tween } 2 \text { and } 8 \text { ) with equal allocation to each } \\
\text { treatment }\end{array}$ \\
\hline Allocation concealment? & Unclear risk & $\begin{array}{l}\text { It was stated that there was allocation con- } \\
\text { cealment, but the method of allocation } \\
\text { concealment was not mentioned }\end{array}$ \\
\hline
\end{tabular}

alphaHBDH: alpha hydroxybutyrate dehydrogenase

ATP: adenosine triphosphate

CK: creatine kinase

CK-MB: creatine kinase MB

ECG: electrocardiogram

EF: ejection fraction

GNA: gated nuclear angiography

hsCRP: hyper-sensitivity C-reactive protein

ITT: intention-to-treat

LDH1: lactate dehydrogenase

LVESWS: left ventricular end-systolic wall stress

MCI: maximal cardiac index

RCT: randomised controlled trial

RR: risk ratio

SD: standard deviation

SF: shortening fraction

SVI: stress-velocity index 
Characteristics of excluded studies [ordered by study ID]

\begin{tabular}{ll}
\hline Study & Reason for exclusion \\
\hline Garcia 2007 & Not RCT or CCT \\
\hline Ginsberg 2004 & $\begin{array}{l}\text { Health-related quality of life was assessed in participants of the AAA trial (Silber 2004), but outcomes were not } \\
\text { related to the treatment allocation }\end{array}$ \\
\hline Shaddy 2007 & $\begin{array}{l}\text { In consultation with the authors of the paper: people with anthracycline-induced cardiomyopathy were included in } \\
\text { the trial, but it was not possible to separate the data of these participants from the data of all included participants }\end{array}$ \\
\hline Tallaj 2005 & Not RCT or CCT \\
\hline Vatutin 2001 & Exclusion based on adult age \\
\hline
\end{tabular}

AAA trial: ACE inhibitor After Anthracycline trial

CCT: controlled clinical trial

RCT: randomised controlled trial

\section{Characteristics of studies awaiting assessment [ordered by study ID]}

\section{Mandric 2008}

\begin{tabular}{ll}
\hline Methods & CCT comparing enalapril to placebo \\
\hline Participants & $\begin{array}{l}30 \text { survivors of paediatric haematological malignancies, aged between } 6 \text { and } 14 \text { years and treated with doxorubicin. } \\
\text { All participants had at least } 1 \text { cardiac abnormality identified at any time after anthracyclines exposure } \\
\text { Enalapril group: } 10 \text { children, mean age at diagnosis } 6 \text { years, mean or median follow-up } 16 \text { months } \\
\text { Placebo group: } 20 \text { children. Mean age and follow-up not mentioned } \\
\text { Both groups had been treated with similar doses of anthracyclines. No further participant characteristics were provided. } \\
\text { Duration of follow-up was unclear }\end{array}$ \\
\hline Interventions & $\begin{array}{l}\text { Enalapril (dose range between } 0.2 \text { and } 0.5 \text { mg/kg/day) } \\
\text { Placebo (not further specified) }\end{array}$ \\
\hline Outcomes & $\begin{array}{l}\text { Cardiac evaluation (including echocardiography) at baseline and at 3, } 6,12,16 \text { months after initiation of enalapril/ } \\
\text { placebo therapy } \\
\text { In the enalapril group, progressive improvement in LV dimensions (end-systolic and end-diastolic), fractional short- } \\
\text { ening, LV mass, LV per cent posterior wall thickening, interventricular per cent septal thickening, and Tei index was } \\
\text { found } \\
\text { In the placebo group, the same echocardiographic parameters were constant or worsened in the course of follow-up } \\
\text { (not further specified) }\end{array}$ \\
\hline $\begin{array}{l}\text { This study has not been published in full text, but was presented at the SIOP conference 2008 (abstract L.030). It } \\
\text { seems that children were not randomised. Completeness of follow-up was not mentioned }\end{array}$ \\
\hline Notes
\end{tabular}

Medical interventions for treating anthracycline-induced symptomatic and asymptomatic cardiotoxicity during and after treatment for 
Mandric 2009

\begin{tabular}{|c|c|}
\hline Methods & Unclear (possibly a CCT) \\
\hline Participants & $\begin{array}{l}27 \text { children aged between } 3 \text { and } 18 \text { years } \\
\text { Enalapril group: } 10 \text { children with subclinical cardiotoxicity on echocardiography } \\
\text { No "cardioprotector" group: } 6 \text { children with a chemotherapeutic protocol completed. It was not specified if this } \\
\text { group suffered from cardiotoxicity } \\
\text { Newly diagnosed group: } 11 \text { children with newly diagnosed cancer. It was not specified if this group received an } \\
\text { intervention } \\
\text { No further participant characteristics were provided. Duration of follow-up was unclear }\end{array}$ \\
\hline Interventions & $\begin{array}{l}\text { Enalapril (not further specified) } \\
\text { No "cardioprotector" (not further specified) }\end{array}$ \\
\hline Outcomes & $\begin{array}{l}\text { Periodic history and physical examination, electrocardiogram, chest X-ray, 2-dimensional/Doppler echocardiography, } \\
\text { cardiac biomarkers (BNP, cTnI, ALAT, CPK) } \\
\text { "Clinical manifestations": heart failure: } 1 \text { participant; "untypical manifestation": } 15 \text { participants; "echocardiographic } \\
\text { modifications": } 6 \text { participants; electrocardiographic changes: } 5 \text { participants; high values of plasma BNP (cutoff value } \\
\text { of } 100 \text { microgram/ml): } 11 \text { participants } \\
\text { The differences in these outcomes between subgroups were not mentioned, except that all children on "cardiopro- } \\
\text { tector" treatment had normal values of BNP and cTnI }\end{array}$ \\
\hline Notes & $\begin{array}{l}\text { This study has not been published in full text, but was presented at the SIOP conference } 2009 \text { (abstract PQ.020). } \\
\text { The title suggested that cardiotoxicity in children in the "no cardioprotector group" (and possibly also in the "newly } \\
\text { diagnosed group") was caused by anthracyclines. It seems that participants were not randomised. Completeness of } \\
\text { follow-up was not mentioned }\end{array}$ \\
\hline
\end{tabular}

ALAT: alanine transaminase

BNP: brain natriuretic peptide

CCT: controlled clinical trial

CPK: creatine phosphokinase

cTnI: cardiac troponin I

LV: left ventricular

SIOP: Société Internationale d'Oncologie Pédiatrique (International Society of Paediatric Oncology)

\section{Characteristics of ongoing studies [ordered by study ID]}

\section{NCT00003070}

\begin{tabular}{ll} 
Trial name or title & $\begin{array}{l}\text { Afterload reduction therapy for late anthracycline cardiotoxicity: a pediatric oncology group cancer control } \\
\text { study }\end{array}$ \\
\hline Methods & $\begin{array}{l}\text { Randomised, double-blinded, phase III trial to compare the effectiveness of enalapril with a placebo in treating } \\
\text { heart damage in people who received anthracycline chemotherapy for childhood cancer }\end{array}$ \\
\hline Participants & $\begin{array}{l}\text { People with histologically diagnosed childhood malignancy who had prior anthracycline therapy and echocar- } \\
\text { diographic evidence of reduced fractional shortening, reduced contractility, or increased afterload, or any }\end{array}$
\end{tabular}




\section{NCT00003070 (Continued)}

combination of these. At least 6 months oncologic disease-free. At least 8 years old at study entry and less than 22 years at diagnosis. At least 1 year since prior cumulative anthracycline therapy of at least $200 \mathrm{mg} / \mathrm{m}^{2}$

Interventions $\quad$ Enalapril maleate and placebo

Outcomes Body surface area-adjusted left ventricular mass, ventricular function, quality of life

Starting date $\quad 15$ August 1997

Contact information Stephen Lipshultz, James P. Wilmot Cancer Center

Notes On the ongoing-trial website there is a note about the recruitment status: completed. However, we found no publication of this trial. One of the review authors (LK) learned from contacts in the US that this trial has as yet not been executed 
DATA AND ANALYSES

Comparison 1. Enalapril versus placebo

\begin{tabular}{lccll} 
Outcome or subgroup title & $\begin{array}{c}\text { No. of } \\
\text { studies }\end{array}$ & $\begin{array}{c}\text { No. of } \\
\text { participants }\end{array}$ & \multicolumn{1}{c}{ Statistical method } & Effect size \\
\hline $\begin{array}{l}\text { 1 Development of clinical heart } \\
\text { failure }\end{array}$ & 1 & 135 & Risk Ratio (M-H, Random, 95\% CI) & $0.16[0.02,1.29]$ \\
2 Dizziness or hypotension & 1 & 135 & Risk Ratio (M-H, Random, 95\% CI) & $7.17[1.71,30.17]$ \\
3 Rash or hives & 1 & 135 & Risk Ratio (M-H, Random, 95\% CI) & $0.96[0.25,3.67]$ \\
4 Heart palpitations & 1 & 135 & Risk Ratio (M-H, Random, 95\% CI) & $3.83[0.44,33.35]$ \\
5 Anxiety or depression & 1 & 135 & Risk Ratio (M-H, Random, 95\% CI) & $1.91[0.18,20.60]$ \\
6 Headache & 1 & 135 & Risk Ratio (M-H, Random, 95\% CI) & $3.83[0.44,33.35]$ \\
7 Gastrointestinal disturbance & 1 & 135 & Risk Ratio (M-H, Random, 95\% CI) & $0.96[0.20,4.57]$ \\
8 Hepatitis C & 1 & 135 & Risk Ratio (M-H, Random, 95\% CI) & $0.64[0.11,3.70]$ \\
9 Neutropenia & 1 & 135 & Risk Ratio (M-H, Random, 95\% CI) & $0.48[0.04,5.15]$ \\
10 Musculoskeletal pain & 1 & 135 & Risk Ratio (M-H, Random, 95\% CI) & $0.96[0.20,4.57]$ \\
11 Dry cough & 1 & 135 & Risk Ratio (M-H, Random, 95\% CI) & $0.96[0.06,14.98]$ \\
12 Shortness of breath & 1 & 135 & Risk Ratio (M-H, Random, 95\% CI) & $0.96[0.14,6.59]$ \\
13 Chest pain & 1 & 135 & Risk Ratio (M-H, Random, 95\% CI) & $1.67[0.51,5.45]$ \\
\hline
\end{tabular}

\section{Analysis I.I. Comparison I Enalapril versus placebo, Outcome I Development of clinical heart failure.}

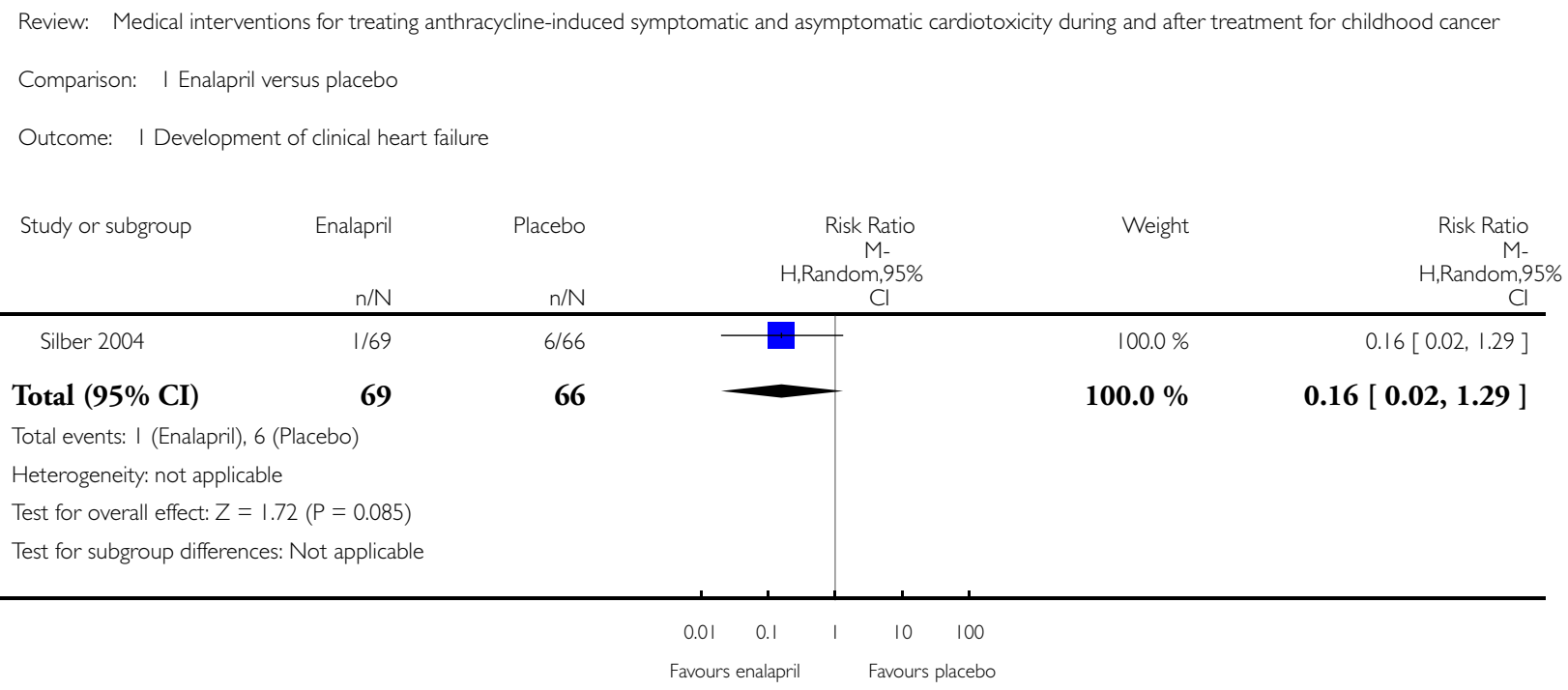




\section{Analysis I.2. Comparison I Enalapril versus placebo, Outcome 2 Dizziness or hypotension.}

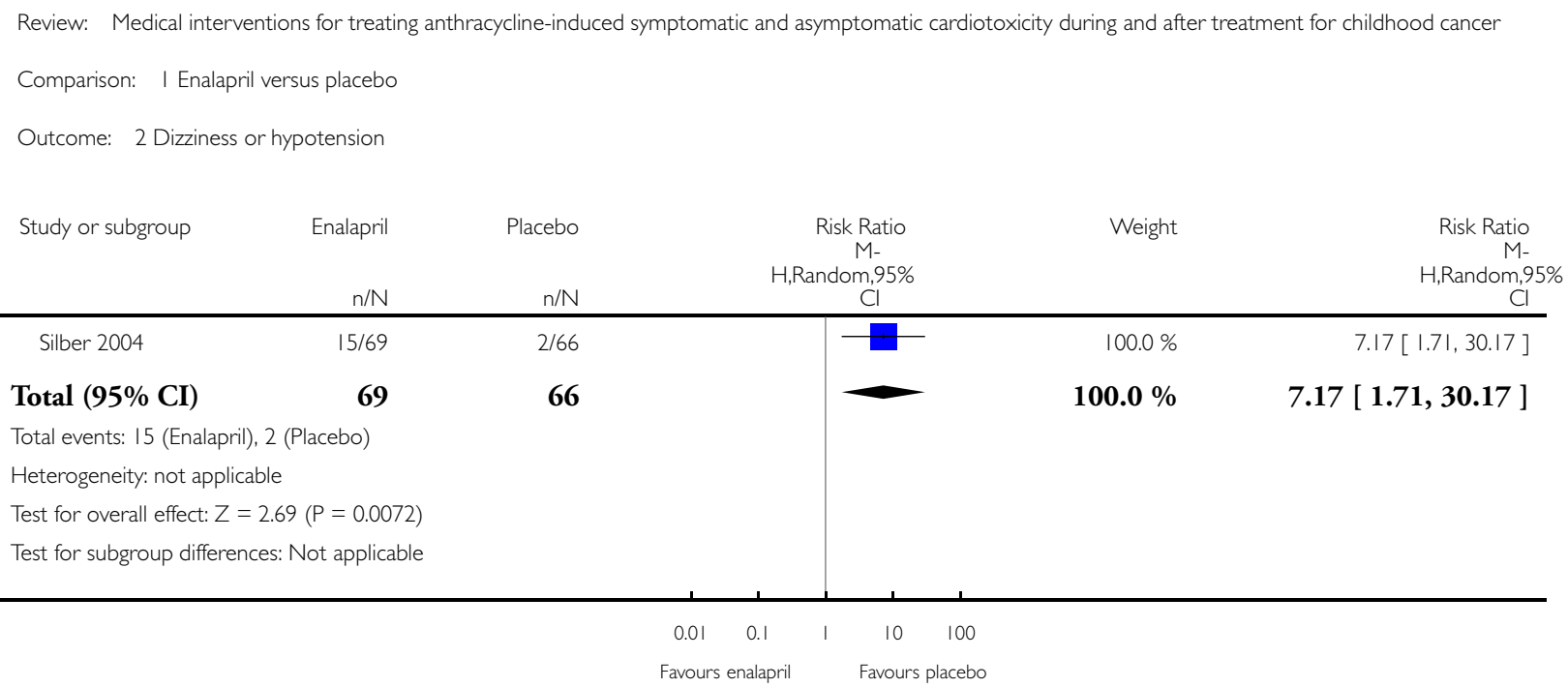

\section{Analysis I.3. Comparison I Enalapril versus placebo, Outcome 3 Rash or hives.}

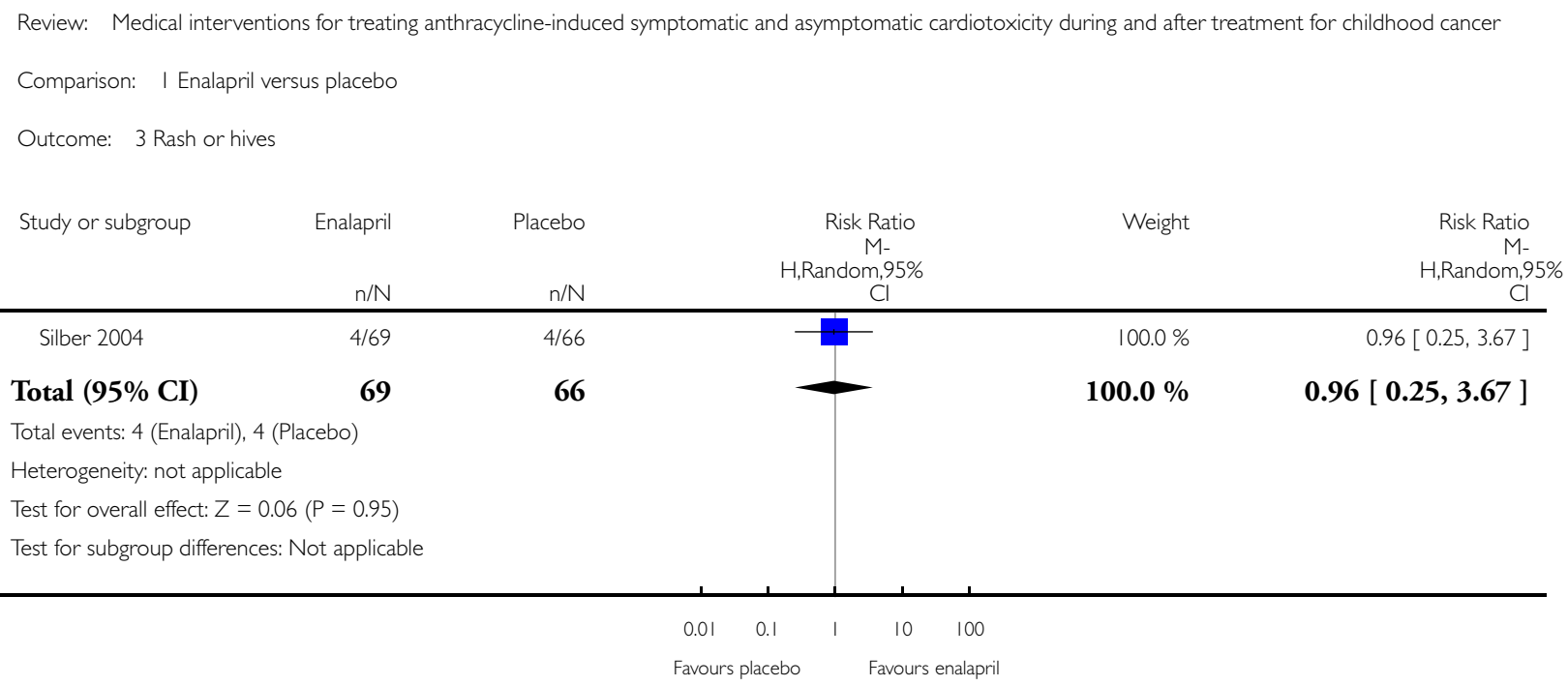




\section{Analysis I.4. Comparison I Enalapril versus placebo, Outcome 4 Heart palpitations.}

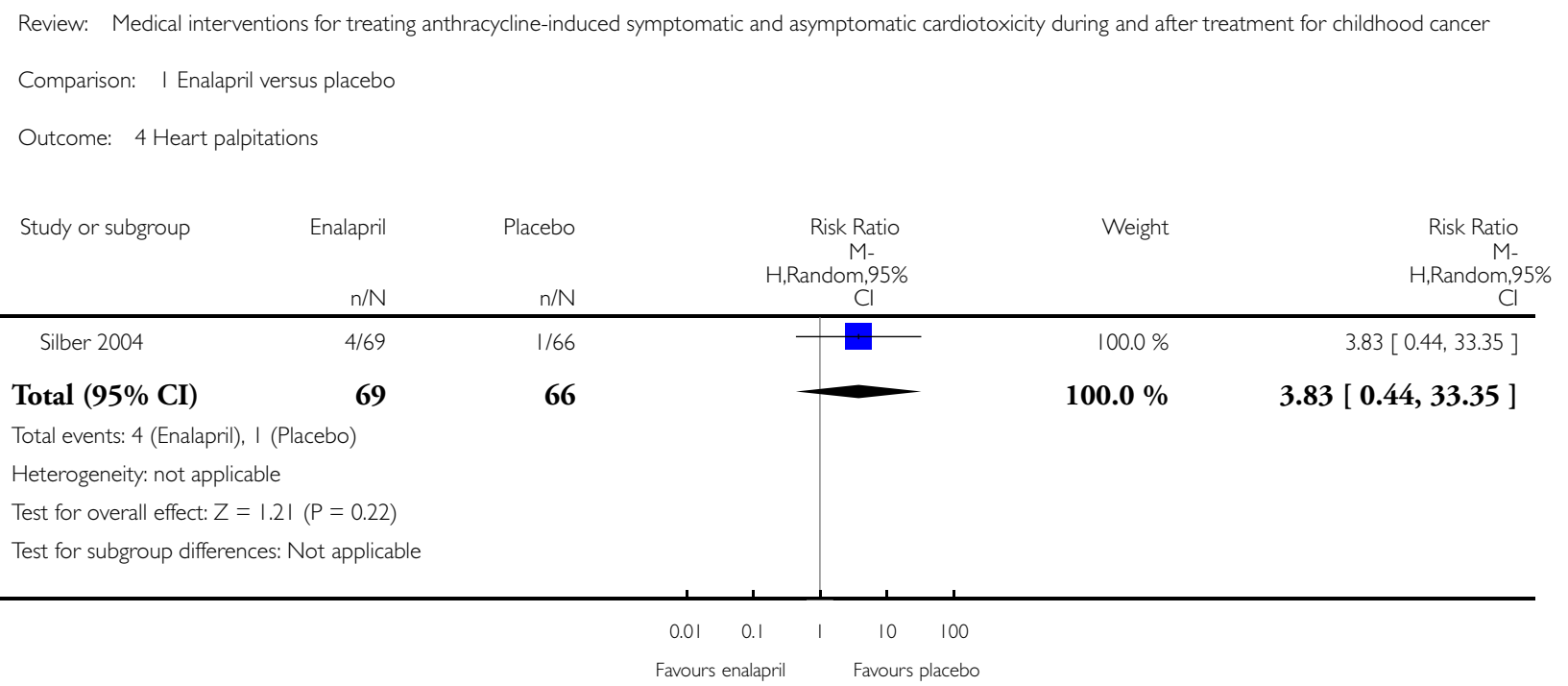

\section{Analysis I.5. Comparison I Enalapril versus placebo, Outcome 5 Anxiety or depression.}

Review: Medical interventions for treating anthracycline-induced symptomatic and asymptomatic cardiotoxicity during and after treatment for childhood cancer

Comparison: I Enalapril versus placebo

Outcome: 5 Anxiety or depression

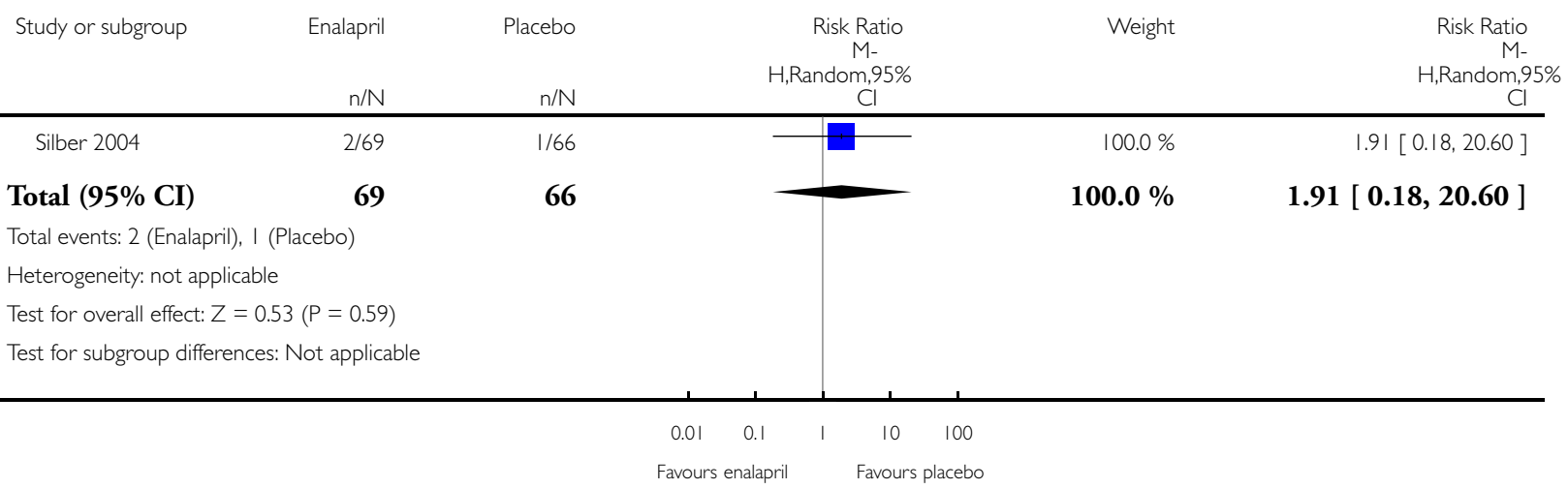

Medical interventions for treating anthracycline-induced symptomatic and asymptomatic cardiotoxicity during and after treatment for 


\section{Analysis I.6. Comparison I Enalapril versus placebo, Outcome 6 Headache.}

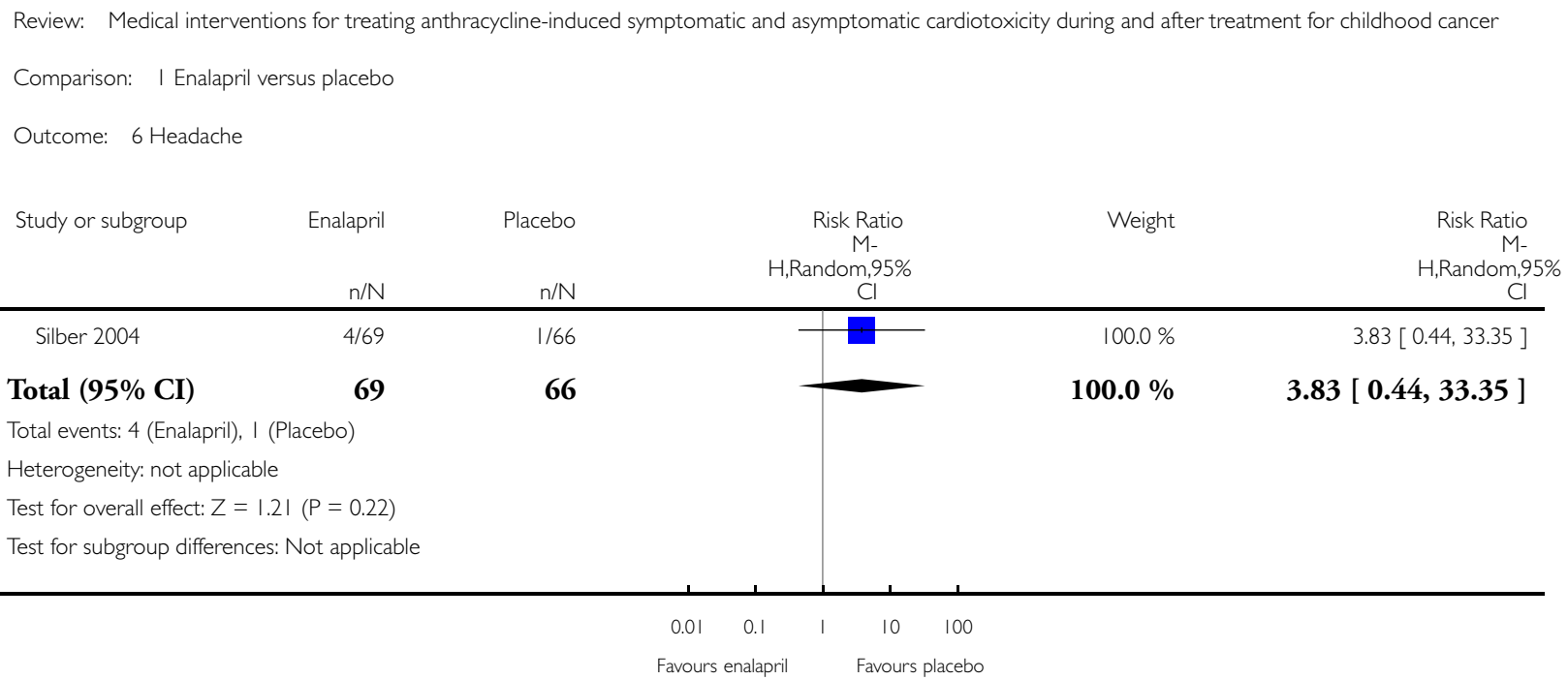

\section{Analysis I.7. Comparison I Enalapril versus placebo, Outcome 7 Gastrointestinal disturbance.}

Review: Medical interventions for treating anthracycline-induced symptomatic and asymptomatic cardiotoxicity during and after treatment for childhood cancer

Comparison: I Enalapril versus placebo

Outcome: 7 Gastrointestinal disturbance

$\begin{array}{llll}\text { Study or subgroup } & \text { Enalapril } & \text { Risk Ratio } & \text { Wisk Ratio }\end{array}$

M- $M$ -

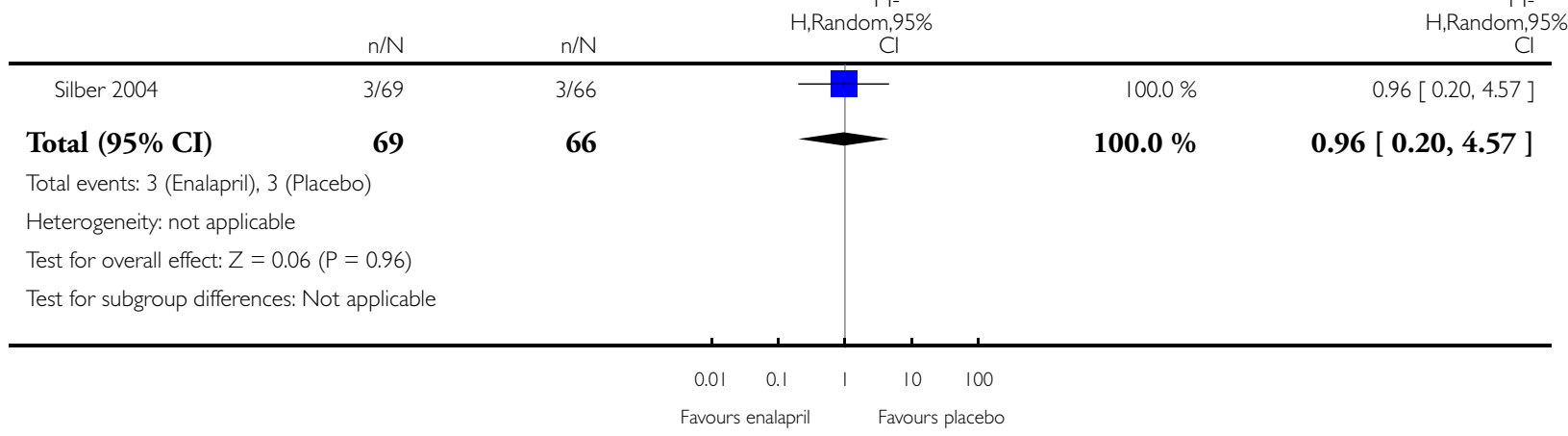

Medical interventions for treating anthracycline-induced symptomatic and asymptomatic cardiotoxicity during and after treatment for 


\section{Analysis I.8. Comparison I Enalapril versus placebo, Outcome 8 Hepatitis C.}

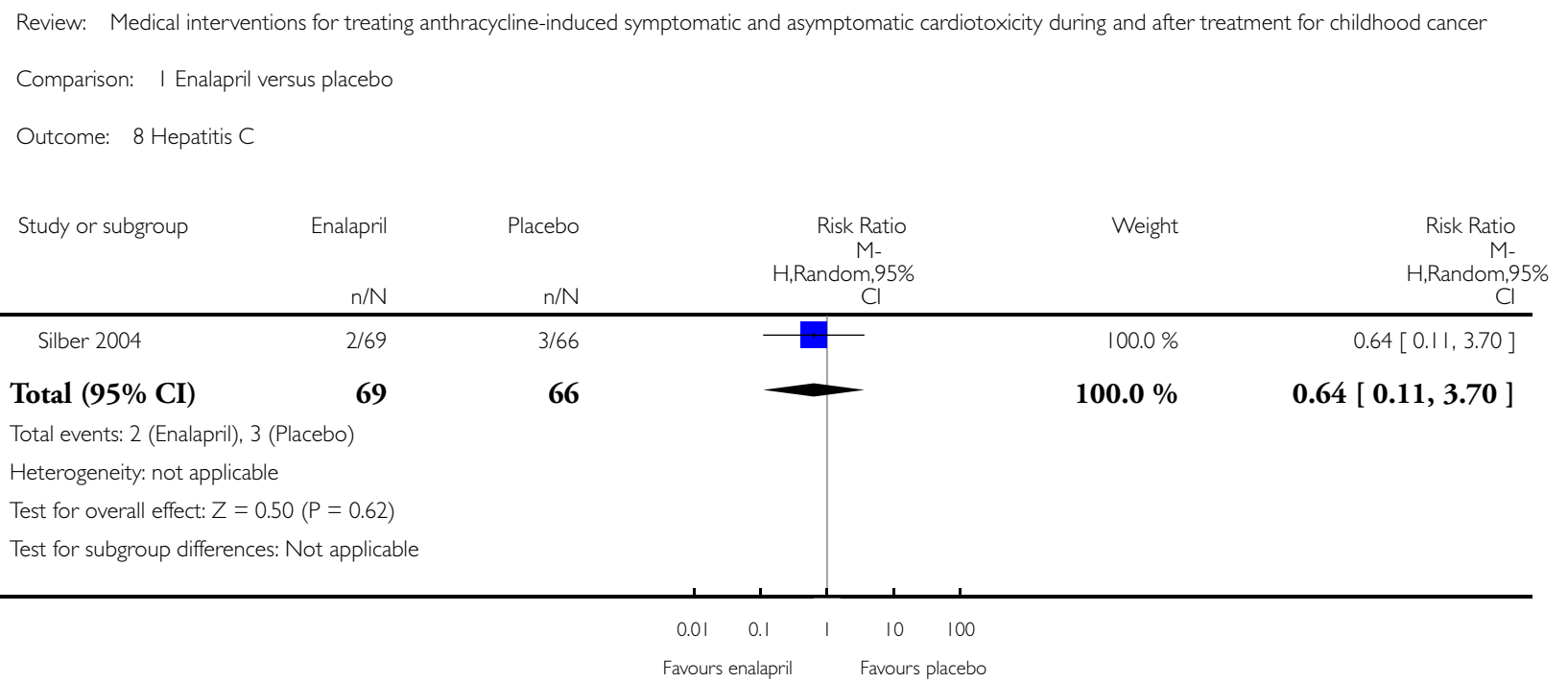

Analysis I.9. Comparison I Enalapril versus placebo, Outcome 9 Neutropenia.

Review: Medical interventions for treating anthracycline-induced symptomatic and asymptomatic cardiotoxicity during and after treatment for childhood cancer

Comparison: I Enalapril versus placebo

Outcome: 9 Neutropenia

$\begin{array}{llll}\text { Study or subgroup } & \text { Enalapril } & \text { Risk Ratio } & \text { Wisk Ratio }\end{array}$

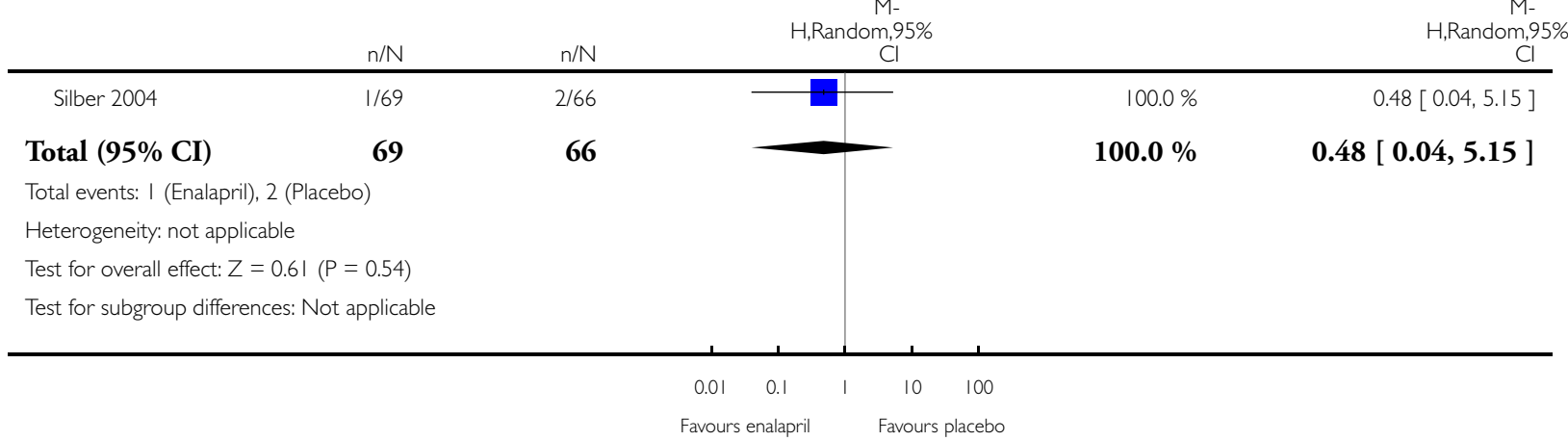

Medical interventions for treating anthracycline-induced symptomatic and asymptomatic cardiotoxicity during and after treatment for 


\section{Analysis I.10. Comparison I Enalapril versus placebo, Outcome 10 Musculoskeletal pain.}

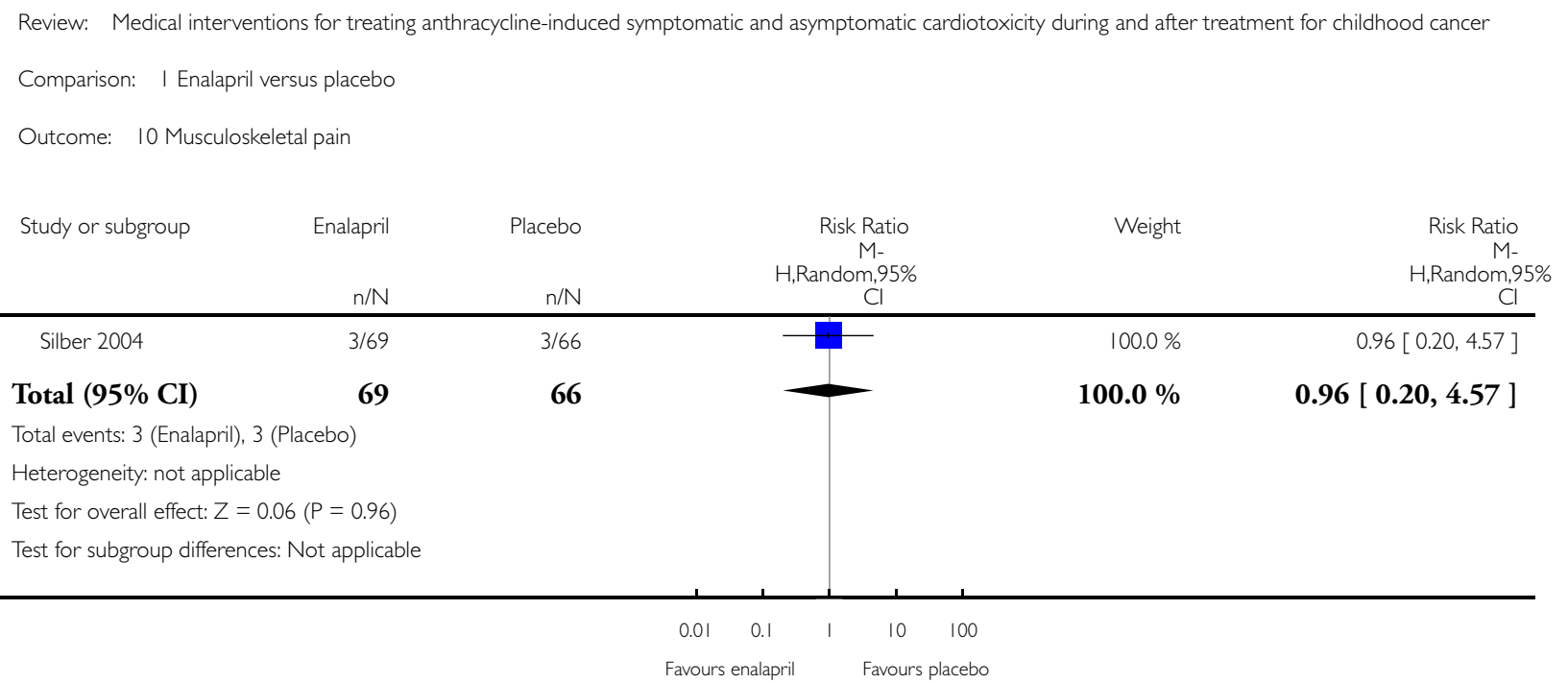

Analysis I.I I. Comparison I Enalapril versus placebo, Outcome I I Dry cough.

Review: Medical interventions for treating anthracycline-induced symptomatic and asymptomatic cardiotoxicity during and after treatment for childhood cancer

Comparison: I Enalapril versus placebo

Outcome: II Dry cough

$\begin{array}{llll}\text { Study or subgroup } & \text { Enalapril } & \text { Placebo Ratio } & \text { Weight }\end{array}$

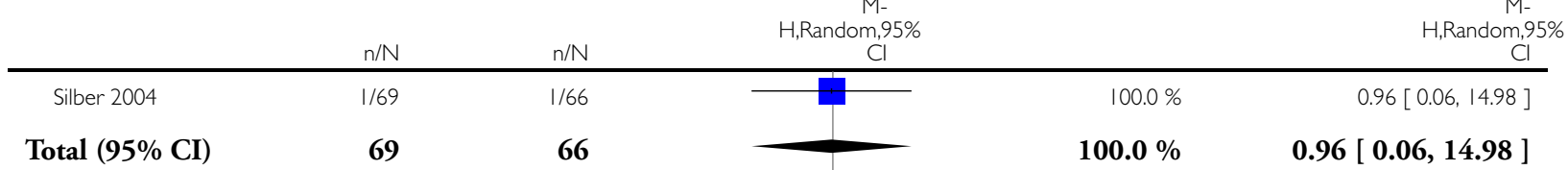

Total events: I (Enalapril), I (Placebo)

Heterogeneity: not applicable

Test for overall effect: $Z=0.03(P=0.97)$

Test for subgroup differences: Not applicable

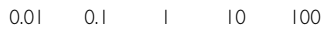

Favours enalapril Favours placebo

Medical interventions for treating anthracycline-induced symptomatic and asymptomatic cardiotoxicity during and after treatment for 


\section{Analysis I.12. Comparison I Enalapril versus placebo, Outcome 12 Shortness of breath.}

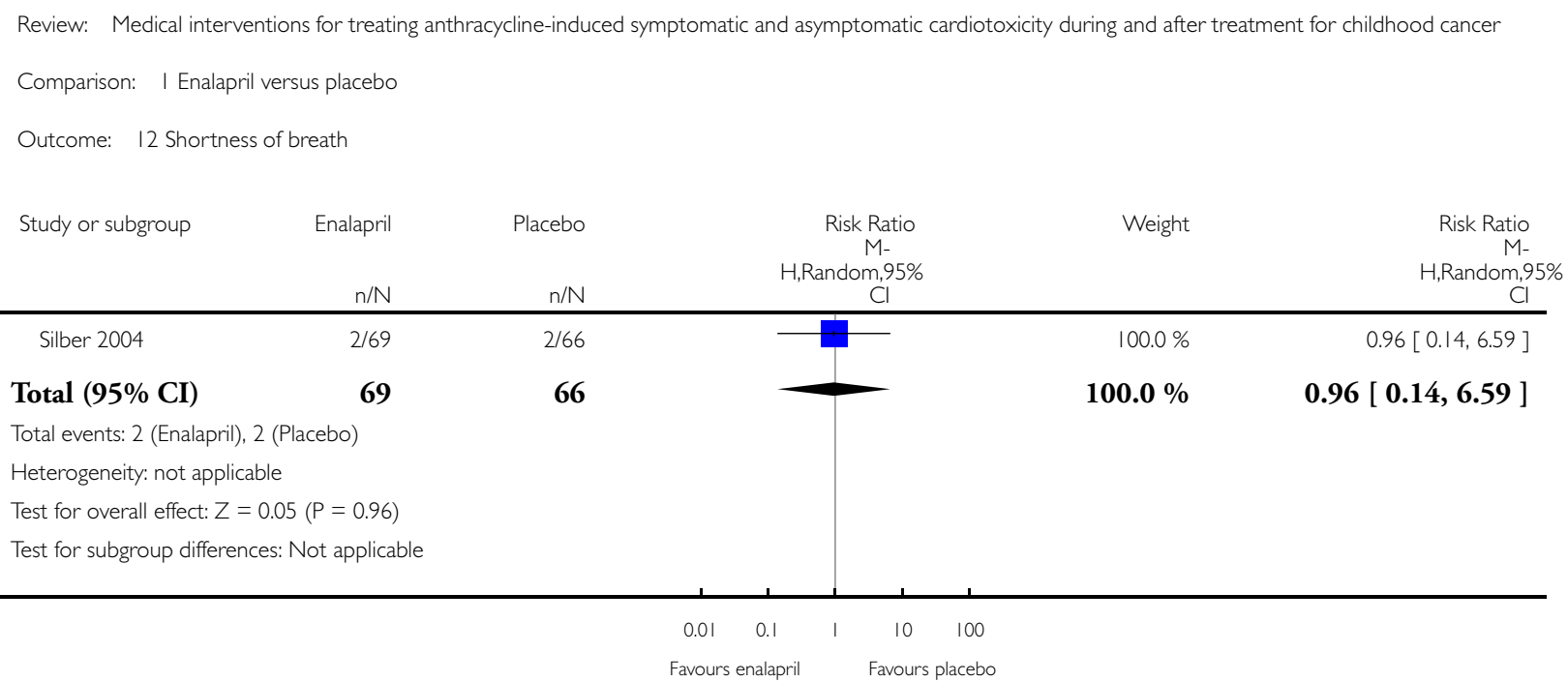

\section{Analysis I.13. Comparison I Enalapril versus placebo, Outcome 13 Chest pain.}

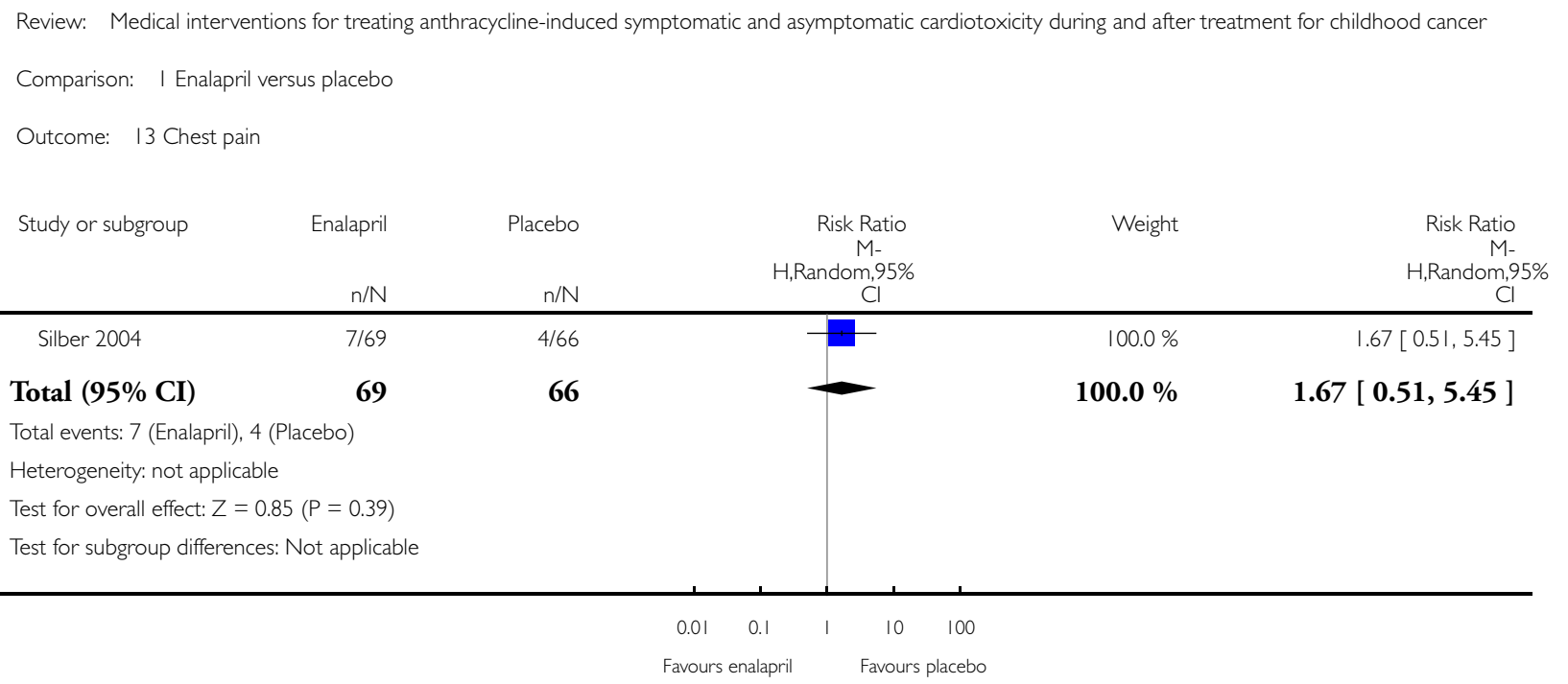

Medical interventions for treating anthracycline-induced symptomatic and asymptomatic cardiotoxicity during and after treatment for 


\section{ADDITIONAL TABLES}

Table 1. Criteria list for the assessment of risk of bias of included studies

\begin{tabular}{l|l|l}
\hline Item ID & Description & Implementation \\
\hline Selection bias & Was the allocation sequence adequately generated? & $\begin{array}{l}\text { Adequate when a random (and therefore unpredictable) se- } \\
\text { quence was used to allocate the intervention to the partici- } \\
\text { pants }\end{array}$ \\
\hline a & Was allocation adequately concealed? & $\begin{array}{l}\text { Adequate when the upcoming allocations of participants } \\
\text { were masked from those involved in enrolment into the trial }\end{array}$ \\
\hline b & Was knowledge of the allocated intervention by participants & $\begin{array}{l}\text { Adequate when the participants were unaware of the inter- } \\
\text { vention they received }\end{array}$ \\
\hline adequately prevented during the study? & $\begin{array}{l}\text { Was knowledge of the allocated intervention by personnel ade- } \\
\text { quately prevented during the study? }\end{array}$ & $\begin{array}{l}\text { Adequate when the personnel involved in the care of the } \\
\text { participants were unaware of the intervention a participant } \\
\text { received }\end{array}$ \\
\hline d & \begin{tabular}{ll} 
Pias \\
\hline
\end{tabular}
\end{tabular}

\section{Detection bias (for each outcome separately)}

e Was knowledge of the allocated intervention by the outcome assessor adequately prevented during the study?

Adequate when the outcome assessor was unaware of the intervention a participant received

\section{Attrition bias (for each outcome separately)}

f Was the follow-up of the outcome complete?

g
Complete when the outcome was assessed in at least $80 \%$ of the study cohort

Adequate when all participants were analysed in the treatment group to which they were randomised, regardless of whether or not they received the allocated intervention

\section{Reporting bias}

$\mathbf{h} \quad$ Are reports of the study free of the suggestion of selective outcome reporting?
Adequate when a study protocol was available that prespecified study outcomes and analyses, which were all reported in the final study report

\section{Other sources of bias}

i Was the study apparently free of other problems that could put it at a high risk of bias?
Adequate when there were no other important personal concerns about bias not addressed in the other domains in the tool

All items were scored yes, no, or unclear.

Medical interventions for treating anthracycline-induced symptomatic and asymptomatic cardiotoxicity during and after treatment for 
Table 2. Fisher's exact test of outcomes with no events in the enalapril or placebo group

\begin{tabular}{|c|c|c|c|}
\hline Outcome & Enalapril $(n=69)$ & Placebo $(n=66)$ & P value \\
\hline Dehydration & 0 & 1 & 0.49 \\
\hline Fatigue & 7 & 0 & 0.013 \\
\hline Fever & 0 & 1 & 0.49 \\
\hline Alopecia & 1 & 0 & 1.00 \\
\hline Severe sunburn & 0 & 1 & 0.49 \\
\hline $\begin{array}{l}\text { Wolff-Parkinson-White } \\
\text { syndrome }\end{array}$ & 0 & 1 & 0.49 \\
\hline Anorexia & 0 & 2 & 0.24 \\
\hline Cholecystitis or gallstones & 2 & 0 & 0.50 \\
\hline Elevated bilirubin & 1 & 0 & 1.00 \\
\hline Ulcerative colitis & 0 & 1 & 0.49 \\
\hline Diabetes & 0 & 1 & 0.49 \\
\hline Hypokalaemia & 0 & 1 & 0.49 \\
\hline Hyperthyroidism & 1 & 0 & 1.00 \\
\hline Second cancer & 2 & 0 & 0.50 \\
\hline Tumour recurrence & 0 & 1 & 0.49 \\
\hline Proteinuria & 1 & 0 & 1.00 \\
\hline Renal stones & 1 & 0 & 1.00 \\
\hline Epistaxis & 1 & 0 & 1.00 \\
\hline Impotence & 0 & 1 & 0.49 \\
\hline Taste disturbance & 1 & 0 & 1.00 \\
\hline
\end{tabular}




\section{A P P E N D I C E S}

\section{Appendix I. Search strategy for Central Register of Controlled Trials (CENTRAL)}

Medical interventions:

\section{ACE-inhibitor}

(ace inhibitor OR ace-inhibitor OR ace inhibitor* OR ace-inhibitor* OR Angiotensin-Converting Enzyme Inhibitors OR Angiotensin Converting Enzyme Inhibitors OR Angiotensin-Converting Enzyme Antagonists OR Angiotensin Converting Enzyme Antagonists OR ACE Inhibitors OR Kininase II Inhibitors OR Kininase II Antagonists OR Angiotensin I-Converting Enzyme Inhibitors OR Angiotensin I Converting Enzyme Inhibitors OR Angiotensin-Converting Enzyme Inhibitor* OR Angiotensin Converting Enzyme Inhibitor* OR Angiotensin-Converting Enzyme Antagonist* OR Angiotensin Converting Enzyme Antagonist* OR Kininase II Inhibitor* OR Kininase II Antagonist* OR Angiotensin I-Converting Enzyme Inhibitor* OR Angiotensin I Converting Enzyme Inhibitor* OR captopril OR enalapril OR fosinopril OR peptidyl dipeptidase OR Peptidyl Dipeptidase A OR Angiotensin I-Converting Enzyme OR Angiotensin I Converting Enzyme OR Carboxycathepsin OR Kininase A OR CD143 Antigen OR CD143 Antigens OR Dipeptidyl Peptidase A OR Angiotensin Converting Enzyme OR Kininase II)

2. Angiotensin receptor blocker

(angiotensin receptor blocker OR angiotensin receptor blockers OR angiotensin receptor blocker* OR Angiotensin II Type 1 Receptor Blockers OR Angiotensin II Type 1 Receptor Antagonists OR Type 1 Angiotensin Receptor Antagonists OR Type 1 Angiotensin Receptor Blockers OR Selective Angiotensin II Receptor Antagonists OR Sartans OR Angiotensin II OR Angiotensin Receptors/ antagonists \& inhibitors OR Angiotensin II Type 1 Receptor Blocker* OR Type 1 Angiotensin Receptor Antagonist* OR Type 1 Angiotensin Receptor Blocker* OR Selective Angiotensin II Receptor Antagonist* OR losartan OR valsartan)

\section{Beta-blocker}

(beta blocker OR beta blockers OR beta-blockers OR beta-blocker OR beta-blocker* OR beta blocker* OR Adrenergic beta Antagonists OR adrenergic beta-antagonists OR Adrenergic beta-Receptor Blockaders OR Adrenergic beta Receptor Blockaders OR beta-Adrenergic Receptor Blockaders OR beta Adrenergic Receptor Blockaders OR beta-Adrenergic Blocking Agents OR beta Adrenergic Blocking Agents OR beta-Adrenergic Blockers OR beta Adrenergic Blockers OR Adrenergic beta-Blockers OR Sympatholytics OR SympatheticBlocking Agents OR Sympathetic Blocking Agents OR Sympatholytic Agents OR Sympatholytic Drugs OR Sympatholytic* OR Adrenergic beta Antagonist* OR Adrenergic beta-Receptor Blockader* OR Adrenergic beta Receptor Blockader* OR beta-Adrenergic Receptor Blockader* OR beta Adrenergic Receptor Blockader* OR beta-Adrenergic Blocking Agent* OR beta Adrenergic Blocking Agent* OR beta Adrenergic Blocker* OR beta-Adrenergic Blocker* OR Adrenergic beta-Blocker* OR Sympathetic-Blocking Agent* OR Sympathetic Blocking Agent* OR Sympatholytic Agent* OR Sympatholytic Drug* OR carvedilol OR atenolol OR metoprolol OR propranolol)

\section{Calcium channel blocker}

(calcium channel blocker OR calcium channel blockers OR calcium channel blocker* OR Exogenous Calcium Antagonists OR Exogenous Calcium Blockaders OR Calcium Channel Blocking Drugs OR Exogenous Calcium Inhibitors OR Exogenous Calcium Antagonist* OR Exogenous Calcium Blockader* OR Calcium Channel Blocking Drug* OR Exogenous Calcium Inhibitor* OR Exogenous Calcium Blockader* OR Calcium Channel Blocking Drug* OR Exogenous Calcium Inhibitor* OR diltiazem OR nifedipine)

\section{Digoxin}

(digoxin OR digoxin* OR Lanoxin)

6. Vasodilator agent

(vasodilator OR vasodilators OR vasodilator* OR vasodilator agents OR Vasodilator Drugs OR Vasoactive Antagonists OR Vasoactive Antagonist* OR vasodilator agent* OR Vasodilator Drug* OR nitroglycerin OR Glyceryl Trinitrate OR Trinitrate, Glyceryl OR Nitroglycerin* OR diazoxide OR adenosine)

\section{Diuretic}

(diuretic OR diuretics OR diuretic* OR furosemide )

8. Aldosterone antagonist

(aldosteron antagonist OR aldosteron antagonists OR aldosterone antagonist OR aldosterone antagonists OR aldosterone antagonist* OR aldosteron antagonist* OR spironolactone)

9. (Other) antihypertensive agents

(antihypertensiva OR anti-hypertensive OR anti hypertensive OR anti hypertensive drugs OR antihypertensive drugs OR antihypertensive agents OR Anti-Hypertensive Agents OR Anti Hypertensive Agents OR Anti-Hypertensive Drugs OR Anti Hypertensive Drugs OR Anti-Hypertensives OR Anti Hypertensives OR Antihypertensive Drugs OR Antihypertensives OR antihypertensiv* OR antihypertensive drug* OR anti hypertensive drug* OR antihypertensive agent* OR anti hypertensive agent* OR clonidine)

Medical interventions for treating anthracycline-induced symptomatic and asymptomatic cardiotoxicity during and after treatment for 


\section{Inotropic}

(inotropics OR inotropic OR inotropic* OR dopamine OR dobutamine OR epinephrine OR norepinephrine)

\section{Growth hormone}

(growth hormone OR Pituitary Growth Hormone OR Somatotropin OR Recombinant Pituitary Growth Hormones OR Recombinant Somatotropin OR Recombinant Growth Hormone OR Recombinant Growth Hormones OR Recombinant Somatotropins OR growth hormon* OR Somatotropin* OR Pituitary Growth Hormon* OR Recombinant Pituitary Growth Hormon* OR Recombinant Somatotropin* OR Recombinant Growth Hormon*)

Total search strategy for medical interventions:

12. 1 OR 2 OR 3 OR 4 OR 5 OR 6 OR 7 OR 8 OR 9 OR 10 OR 11

13. Anthracyclines

anthracyclines OR anthracyclin* OR anthracycline antibiotics OR 4-demethoxydaunorubicin OR 4 demethoxydaunorubicin OR 4desmethoxydaunorubicin OR 4 desmethoxydaunorubicin OR IMI 30 OR IMI30 OR IMI-30 OR idarubicin hydrochloride OR NSC 256439 OR NSC-256439 OR NSC256439 OR idarubicin OR idarubic* OR 4'-epiadriamycin OR 4' epiadriamycin OR 4'epidoxorubicin OR 4' epidoxorubicin OR 4'-epi-doxorubicin OR 4' epi doxorubicin OR 4'-epi-adriamycin OR 4' epi adriamycin OR 4'-epi-DXR OR 4' epi DXR OR epirubicin hydrochloride OR farmorubicin OR IMI-28 OR IMI 28 OR IMI28 OR NSC 256942 OR NSC-256942 OR NSC256942 OR epirubicin OR epirubic* OR adriablastine OR adriblastin OR adriablastin OR adriamycin OR DOX-SL OR DOX SL OR doxorubicin hydrochloride OR doxorubic* OR adriamyc* OR dauno-rubidomycine OR dauno rubidomycin OR rubidomycin OR rubomycin OR daunomycin OR cerubidine OR daunoblastin OR daunoblastine OR daunorubicin hydrochloride OR hydrochloride, daunorubicin OR daunorubic* OR rubidomyc* OR NSC-82151 OR NSC 82151 OR NSC82151 OR daunoxome OR daunoxom* OR daunosom* OR doxil OR caelyx OR liposomal doxorubicin OR myocet OR doxorubicin OR daunorubicin

\section{Childhood cancer}

(leukemia OR leukemi* OR leukaemi* OR (childhood ALL) OR AML OR lymphoma OR lymphom* OR hodgkin* OR T-cell OR B-cell OR non-hodgkin OR sarcoma OR sarcom* OR Ewing* OR osteosarcoma OR osteosarcom* OR wilms tumor OR wilms* OR nephroblastom* OR neuroblastoma OR neuroblastom* OR rhabdomyosarcoma OR rhabdomyosarcom* OR teratoma OR teratom* OR hepatoma OR hepatom* OR hepatoblastoma OR hepatoblastom* OR PNET OR medulloblastoma OR medulloblastom* OR PNET* $^{*}$ OR neuroectodermal tumors, primitive OR retinoblastoma OR retinoblastom* OR meningioma OR meningiom* OR glioma OR gliom* OR pediatric oncology OR paediatric oncology OR childhood cancer OR childhood tumor OR childhood tumors OR cancer or neoplasms or tumor or cancers or neoplasm or tumors)

The final combined search was:

\section{12 AND 13 AND 14}

All searches in Title, Abstract or Keywords in Cochrane Central Register of Controlled Trials (CENTRAL).

$\left[{ }^{*}=\right.$ zero or more characters $]$

\section{Appendix 2. Search strategy for MEDLINE/PubMed}

Medical interventions:

\section{ACE-inhibitor}

(ace inhibitor OR ace-inhibitor OR ace inhibitor* OR ace-inhibitor* OR Angiotensin-Converting Enzyme Inhibitors OR AngiotensinConverting Enzyme Inhibitors[Pharmacological Action] OR Angiotensin Converting Enzyme Inhibitors OR Angiotensin-Converting Enzyme Antagonists OR Angiotensin Converting Enzyme Antagonists OR Enzyme Antagonists, Angiotensin-Converting OR Antagonists, Angiotensin-Converting Enzyme OR Antagonists, Angiotensin Converting Enzyme OR Antagonists, Kininase II OR Inhibitors, Kininase II OR Inhibitors, ACE OR ACE Inhibitors OR Kininase II Inhibitors OR Kininase II Antagonists OR Angiotensin IConverting Enzyme Inhibitors OR Angiotensin I Converting Enzyme Inhibitors OR Inhibitors, Angiotensin-Converting Enzyme OR Enzyme Inhibitors, Angiotensin-Converting OR Inhibitors, Angiotensin Converting Enzyme OR Angiotensin-Converting Enzyme Inhibitor* OR Angiotensin Converting Enzyme Inhibitor* OR Angiotensin-Converting Enzyme Antagonist* OR Angiotensin Converting Enzyme Antagonist* OR Kininase II Inhibitor* OR Kininase II Antagonist* OR Angiotensin I-Converting Enzyme Inhibitor* OR Angiotensin I Converting Enzyme Inhibitor* OR captopril OR enalapril OR fosinopril) OR (peptidyl dipeptidase OR Peptidyl Dipeptidase A OR Angiotensin I-Converting Enzyme OR Angiotensin I Converting Enzyme OR Carboxycathepsin OR Kininase A OR CD143 Antigen OR CD143 Antigens OR Dipeptidyl Peptidase A OR Antigens, CD143 OR Angiotensin Converting Enzyme OR Kininase II)

2. Angiotensin receptor blocker

Medical interventions for treating anthracycline-induced symptomatic and asymptomatic cardiotoxicity during and after treatment for 
(angiotensin receptor blocker OR angiotensin receptor blockers OR angiotensin receptor blocker* OR Angiotensin II Type 1 Receptor Blockers OR Angiotensin II Type 1 Receptor Antagonists OR Type 1 Angiotensin Receptor Antagonists OR Type 1 Angiotensin Receptor Blockers OR Selective Angiotensin II Receptor Antagonists OR Sartans OR Angiotensin II OR Angiotensin Receptors/ antagonists \& inhibitors OR Angiotensin II Type 1 Receptor Blocker* OR Type 1 Angiotensin Receptor Antagonist* OR Type 1 Angiotensin Receptor Blocker* OR Selective Angiotensin II Receptor Antagonist* OR losartan OR valsartan)

\section{Beta-blocker}

(beta blocker OR beta blockers OR beta-blockers OR beta-blocker OR beta-blocker* OR beta blocker* OR Adrenergic beta Antagonists OR adrenergic beta-antagonists OR adrenergic beta-antagonists[Pharmacological Action] OR beta-Antagonists, Adrenergic OR Adrenergic beta-Receptor Blockaders OR Adrenergic beta Receptor Blockaders OR Blockaders, Adrenergic beta-Receptor OR beta-Receptor Blockaders, Adrenergic OR beta-Adrenergic Receptor Blockaders OR Blockaders, beta-Adrenergic Receptor OR Receptor Blockaders, beta-Adrenergic OR beta Adrenergic Receptor Blockaders OR beta-Adrenergic Blocking Agents OR Agents, beta-Adrenergic Blocking OR Blocking Agents, beta-Adrenergic OR beta Adrenergic Blocking Agents OR beta-Adrenergic Blockers OR Blockers, beta-Adrenergic OR beta Adrenergic Blockers OR beta-Blockers, Adrenergic OR Adrenergic beta-Blockers OR beta Blockers, Adrenergic OR Sympatholytics OR Sympatholytics[Pharmacological Action] OR Sympathetic-Blocking Agents OR Agents, Sympathetic-Blocking OR Sympathetic Blocking Agents OR Sympatholytic Agents OR Agents, Sympatholytic OR Sympatholytic Drugs OR Drugs, Sympatholytic OR Sympatholytic* OR Adrenergic beta Antagonist* OR Adrenergic beta-Receptor Blockader* OR Adrenergic beta Receptor Blockader* OR beta-Adrenergic Receptor Blockader* OR beta Adrenergic Receptor Blockader* OR beta-Adrenergic Blocking Agent* OR beta Adrenergic Blocking Agent* OR beta Adrenergic Blocker* OR beta-Adrenergic Blocker* OR Adrenergic beta-Blocker* OR Sympathetic-Blocking Agent* OR Sympathetic Blocking Agent* OR Sympatholytic Agent* OR Sympatholytic Drug* OR carvedilol OR atenolol OR metoprolol OR propranolol)

\section{Calcium channel blocker}

(calcium channel blocker OR calcium channel blockers OR calcium channel blockers[Pharmacological Action] OR calcium channel blocker* OR Exogenous Calcium Antagonists OR Antagonists, Exogenous Calcium OR Calcium Antagonists, Exogenous OR Exogenous Calcium Blockaders OR Blockaders, Exogenous Calcium OR Calcium Inhibitors, Exogenous OR Calcium Channel Blocking Drugs OR Exogenous Calcium Inhibitors OR Inhibitors, Exogenous Calcium OR Calcium Blockaders, Exogenous OR Channel Blockers, Calcium OR Blockers, Calcium Channel OR Exogenous Calcium Antagonist* OR Exogenous Calcium Blockader* OR Calcium Channel Blocking Drug* OR Exogenous Calcium Inhibitor* OR Exogenous Calcium Blockader* OR Calcium Channel Blocking Drug* OR Exogenous Calcium Inhibitor* OR diltiazem OR nifedipine)

\section{Digoxin}

(digoxin OR digoxin* OR Lanoxin)

6. Vasodilator agent

(vasodilator OR vasodilators OR vasodilator* OR vasodilator agents OR vasodilator agents[Pharmacological Action] OR Agents, Vasodilator OR Vasodilator Drugs OR Drugs, Vasodilator OR Vasoactive Antagonists OR Antagonists, Vasoactive OR Vasoactive Antagonist* OR vasodilator agent* OR Vasodilator Drug* OR nitroglycerin OR Glyceryl Trinitrate OR Trinitrate, Glyceryl OR Nitroglycerin* OR diazoxide OR adenosine)

\section{Diuretic}

(diuretic OR diuretics OR diuretic* OR diuretics[Pharmacological Action] OR furosemide )

\section{Aldosterone antagonist}

(aldosteron antagonist OR aldosteron antagonists OR aldosterone antagonist OR aldosterone antagonists OR aldosterone antagonist* OR aldosteron antagonist* OR “Aldosterone antagonists"[Pharmacological Action] OR Antagonists, Aldosterone OR spironolactone) 9. (Other) antihypertensive agents

(antihypertensiva OR anti-hypertensive OR anti hypertensive OR anti hypertensive drugs OR antihypertensive drugs OR antihypertensive agents OR antihypertensive agents[Pharmacological Action] OR Agents, Antihypertensive OR Anti-Hypertensive Agents OR Agents, Anti-Hypertensive OR Anti Hypertensive Agents OR Anti-Hypertensive Drugs OR Anti Hypertensive Drugs OR Drugs, Anti-Hypertensive OR Anti-Hypertensives OR Anti Hypertensives OR Antihypertensive Drugs OR Drugs, Antihypertensive OR Antihypertensives OR antihypertensiv* OR antihypertensive drug* OR anti hypertensive drug* OR antihypertensive agent* OR anti hypertensive agent* OR clonidine)

\section{Inotropic}

(inotropics OR inotropic OR inotropic* OR dopamine OR dobutamine OR epinephrine OR norepinephrine)

\section{Growth hormone}

(growth hormone OR Growth Hormone, Pituitary OR Pituitary Growth Hormone OR Somatotropin OR Growth Hormone, Recombinant OR Growth Hormones Pituitary, Recombinant OR Pituitary Growth Hormones, Recombinant OR Recombinant Pituitary Growth Hormones OR Somatotropin, Recombinant OR Recombinant Somatotropin OR Recombinant Growth Hormone

Medical interventions for treating anthracycline-induced symptomatic and asymptomatic cardiotoxicity during and after treatment for $4 \mathrm{I}$ childhood cancer (Review)

Copyright $(2016$ The Cochrane Collaboration. Published by John Wiley \& Sons, Ltd. 
OR Recombinant Growth Hormones OR Growth Hormones, Recombinant OR Recombinant Somatotropins OR Somatotropins, Recombinant OR growth hormon* OR Somatotropin* OR Pituitary Growth Hormon* OR Recombinant Pituitary Growth Hormon* OR Recombinant Somatotropin* OR Recombinant Growth Hormon*)

Total search strategy for medical interventions:

12. 1 OR 2 OR 3 OR 4 OR 5 OR 6 OR 7 OR 8 OR 9 OR 10 OR 11

13. Anthracyclines

(anthracyclines OR anthracyclin* OR anthracycline antibiotics OR antibiotics, anthracycline OR 4-demethoxydaunorubicin OR 4 demethoxydaunorubicin OR 4-desmethoxydaunorubicin OR 4 desmethoxydaunorubicin OR IMI 30 OR IMI30 OR IMI-30 OR idarubicin hydrochloride OR hydrochloride, idarubicin OR NSC 256439 OR NSC-256439 OR NSC256439 OR idarubicin OR idarubic* OR 4'-epiadriamycin OR 4' epiadriamycin OR 4'-epidoxorubicin OR 4' epidoxorubicin OR 4'-epi-doxorubicin OR 4' epi doxorubicin OR 4'-epi-adriamycin OR 4' epi adriamycin OR 4'-epi-DXR OR 4' epi DXR OR epirubicin hydrochloride OR hydrochloride, epirubicin OR farmorubicin OR IMI-28 OR IMI 28 OR IMI28 OR NSC 256942 OR NSC-256942 OR NSC256942 OR epirubicin OR epirubic* OR adriablastine OR adriblastin OR adriablastin OR adriamycin OR DOX-SL OR DOX SL OR doxorubicin hydrochloride OR hydrochloride, doxorubicin OR doxorubic* OR adriamyc* OR dauno-rubidomycine OR dauno rubidomycin OR rubidomycin OR rubomycin OR daunomycin OR cerubidine OR daunoblastin OR daunoblastine OR daunorubicin hydrochloride OR hydrochloride, daunorubicin OR daunorubic* OR rubidomyc* OR NSC-82151 OR NSC 82151 OR NSC82151 OR daunoxome OR daunoxom* OR daunosom* OR doxil OR caelyx OR liposomal doxorubicin OR doxorubicin, liposomal OR myocet OR doxorubicin OR daunorubicin)

\section{Childhood cancer}

(((leukemia OR leukemi* OR leukaemi* OR (childhood ALL) OR AML OR lymphoma OR lymphom* OR hodgkin* OR T-cell OR B-cell OR non-hodgkin OR sarcoma OR sarcom* OR sarcoma, Ewing's OR Ewing* OR osteosarcoma OR osteosarcom* OR wilms tumor OR wilms* OR nephroblastom* OR neuroblastoma OR neuroblastom* OR rhabdomyosarcoma OR rhabdomyosarcom* OR teratoma OR teratom* OR hepatoma OR hepatom* OR hepatoblastoma OR hepatoblastom* OR PNET OR medulloblastoma OR medulloblastom* OR PNET* OR neuroectodermal tumors, primitive OR retinoblastoma OR retinoblastom* OR meningioma OR meningiom* OR glioma OR gliom*) OR (pediatric oncology OR paediatric oncology)) OR (childhood cancer OR childhood tumor OR childhood tumors)) OR (cancer or neoplasms or tumor or cancers or neoplasm or tumors)

\section{RCTs, CCTs}

(randomized controlled trial[pt] OR controlled clinical trial[pt] OR randomized[tiab] OR placebo[tiab] OR drug therapy[sh] OR randomly[tiab] OR trial[tiab] OR groups[tiab]) AND humans[mh]

The final combined search was:

\section{12 AND 13 AND 14 AND 15}

[pt = publication type; tiab = title, abstract; $\mathrm{sh}=$ subject heading; $\mathrm{mh}=\mathrm{MeSH}$ term; ${ }^{*}=$ zero or more characters; $\mathrm{RCT}=$ randomized controlled trial; CCT $=$ controlled clinical trial]

\section{Appendix 3. Search strategy for EMBASE/OVID}

\section{Medical interventions}

1. (ace inhibitor or ace-inhibitor or ace inhibitor\$ or ace-inhibitor\$).mp.

2. Dipeptidyl Carboxypeptidase Inhibitor/ or (angiotensin converting enzyme inhibitor or angiotensin converting enzyme inhibitors or angiotensin converting enzyme inhibitor\$).mp.

3. (angiotensin-converting enzyme inhibitor or angiotensin-converting enzyme inhibitors or angiotensin-converting enzyme inhibitor\$).mp.

4. (angiotensin-converting enzyme antagonist or angiotensin-converting enzyme antagonists or angiotensin-converting enzyme antagonist $\$$ or angiotensin converting enzyme antagonist or angiotensin converting enzyme antagonists or angiotensin converting enzyme antagonist\$).mp.

5. (kininase II inhibitor or kininase II inhibitors or kininase II inhibitor\$ or kininase II antagonist or kininase antagonists or kininase antagonist\$).mp.

6. (angiotensin I-converting enzyme inhibitors or angiotensin I converting enzyme inhibitors or angiotensin I-converting enzyme inhibitor\$ or angiotensin I converting enzyme inhibitor\$).mp.

7. (peptidyl dipeptidase or peptidyl dipeptidase A).mp. or exp Dipeptidyl Carboxypeptidase/

8. exp Kininase/ or Kininase A.mp.

9. (Angiotensin I-Converting Enzyme or Angiotensin I Converting Enzyme).mp.

Medical interventions for treating anthracycline-induced symptomatic and asymptomatic cardiotoxicity during and after treatment for 
10. exp Dipeptidyl Peptidase/ or Dipeptidyl Peptidase A.mp.

11. (Carboxycathepsin or Angiotensin Converting Enzyme or Kininase II).mp.

12. (CD143 Antigen or CD143 Antigens).mp.

13. (captopril or enalapril or fosinopril).mp. or exp Captopril Plus Hydrochlorothiazide/ or exp Captopril/ or exp Enalapril Maleate/ or exp Enalapril Plus Hydrochlorothiazide/ or exp Enalapril/ or exp Enalapril Maleate Plus Nitrendipine/ or exp Enalapril Maleate Plus Felodipine/ or exp Diltiazem Plus Enalapril Maleate/ or exp Fosinopril/ [mp=title, abstract, subject headings, heading word, drug trade name, original title, device manufacturer, drug manufacturer name]

14. (angiotensin receptor blocker or angiotensin receptor blockers or angiotensin receptor blocker\$).mp.

15. (angiotensin II type 1 receptor blockers or angiotensin II type 2 receptor blocker\$).mp. or exp Angiotensin Receptor Antagonist/

16. (angiotensin II type 1 receptor antagonists or type 1 angiotensin receptor antagonists or type 1 angiotensin receptor blocker $\$$ or type 1 angiotensin receptor blockers or type 1 angiotensin receptor antagonist $\$$ ).mp.

17. exp Angiotensin Antagonist/ or exp Angiotensin/ or exp Angiotensin 2 Receptor Antagonist/ or exp Angiotensin II Antagonist/

18. (selective angiotensin II receptor antagonists or selective angiotensin II receptor antogonist $\$$ or sartans or angiotensin II).mp.

19. (losartan or valsartan).mp. or exp Losartan/ or exp Hydrochlorothiazide Plus Losartan/ or exp Losartan Potassium/ or exp Hydrochlorothiazide Plus Valsartan/ or exp Amlodipine Plus Valsartan/ or exp Valsartan/

20. (beta blocker or beta blockers or beta blocker\$ or beta-blocker or beta-blockers or beta-blocker\$).mp.

21. exp Beta Adrenergic Receptor Blocking Agent/

22. (adrenergic beta-antagonists or adrenergic beta antagonists).mp.

23. (adrenergic beta-receptor blockaders or adrenergic beta receptor blockaders or beta-adrenergic receptor blockaders or beta adrenergic receptor blockaders).mp.

24. (beta-adrenergic blocking agents or beta adregenic blocking agents or beta-adrenergic blockers or beta adrenergic blockers or adrenergic beta-blockers or adrenergic beta blockers).mp.

25. (sympatholytics or sympathetic-blocking agents or sympathetic blocking agents or sympatholytic agents or sympatholytic drugs or sympatholytic $\$$ ).mp.

26. (adrenergic beta antagonist $\$$ or adrenergic beta-receptor blockader $\$$ or adrenergic beta receptor blockader $\$$ or beta-adrenergic receptor blockader $\$$ or beta adrenergic receptor blockader $\$$ or beta-adrenergic blocking agent $\$$ or beta adrenergic blocking agent $\$$ ).mp. 27. (beta adrenergic blocker\$ or beta-adrenergic blocker\$ or adrenergic beta-blocker\$ or sympathetic-blocking agent $\$$ or sympathetic blocking agent $\$$ or sympatholytic agent $\$$ or sympatholytic drug\$).mp.

28. (carvedilol or atenolol or metoprolol or propanolol).mp. or exp carvedilol/ or exp atenolol plus chlortalidone/ or exp atenolol/ or exp atenolol plus nifedipine/ or exp metoprolol tartrate/ or exp metoprolol/ or exp metoprolol fumarate/ or exp metoprolol succinate/ or exp propranolol/

29. (calcium channel blocker or calcium channel blockers or calcium channel blocker\$).mp.

30. exp Calcium Channel Blocking Agent/

31. exp Calcium Antagonist/ or (exogenous calcium antagonists or exogenous calcium blockaders or calcium channel blocking drugs).mp.

32. (exogenous calcium inhibitors or exogenous calcium antagonist $\$$ or exogenous calcium blockader\$ or calcium channel blocking drug\$).mp.

33. (exogenous calcium inhibitor $\$$ or exogenous calcium blockader $\$$ or calcium channel blocking drug $\$$ or exogenous calcium inhibitor\$).mp.

34. exp Diltiazem Derivative/ or exp Diltiazem/ or exp Diltiazem Plus Enalapril Maleate/ or exp Nefedipine/ or (diltiazem or nefedipine).mp.

35. exp DIGOXIN/

36. (digoxin or digoxin $\$$ or lanoxin).mp.

37. (vasodilator or vasodilators or vasodilator\$).mp.

38. exp Vasodilator Agent/ or (vasodilator agents or vasodilator agent $\$$ or vasodilator drugs or vasodilator drug\$ or vasoactive antagonists or vasoactive antagonist\$).mp.

39. (nitroglycerin or glyceryl trinitrate or nitroglycerin $\$$ or diazoxide or adenosine).mp.

40. exp diazoxide/ or exp glyceryl trinitrate/

41. (diuretic or diuretics or diuretic\$).mp.

42. exp Diuretic Agent/ or exp Furosemide Plus Triamterene/ or exp Furosemide/ or furosemide.mp.

43. (aldosteron antagonist or aldosteron antagonists or aldosterone antagonist aldosterone antagonists or aldosterone antagonist $\$$ ).mp.

44. exp Aldosterone Antagonist/ or spironolacton.mp. or exp Spironolactone/

45. (antihypertensiva or antihypertensive or anti hypertensive or anti-hypertensive).mp.

Medical interventions for treating anthracycline-induced symptomatic and asymptomatic cardiotoxicity during and after treatment for 
46. exp Antihypertensive Agent/

47. (anti hypertensive drugs or anti-hypertensive drugs or antihypertensive drugs or antihypertensive agents or anti-hypertensive agents or anti hypertensive agents).mp.

48. (anti-hypertensives or anti hypertensives or antihypertensives).mp.

49. (antihypertensiv $\$$ or antihypertensive drug $\$$ or anti hypertensive drug $\$$ or antihypertensive agent $\$$ or anti hypertensive agent $\$$ ).mp.

50. exp Clonidine Derivative/ or clonidine.mp. or exp Clonidine/ or exp Clonidine Displacing Substance/

51. (inotropic or inotropics or inotropic\$).mp.

52. exp dopamine/ or exp dobutamine/ or exp adrenalin/ or exp noradrenaline/ or (dopamine or dobutamine or epinephrine or norepinephrine).mp.

53. (growth hormone or pituitary growth hormone).mp. or exp Growth Hormone/

54. (somatropin or recombinant somatotropin).mp. or exp recombinant growth hormone/ or recombinant pituitary growth hormones.mp.

55. (recombinant growth hormone or recombinant growth hormones or recombinant somatotropins).mp.

56. (growth hormon\$ or somatotropin\$ or pituitary growth hormon\$ or recombinant pituitary growth hormon\$ or recombinant somatotropin\$ or recombinant growth hormon\$).mp.

57. or/1-56

2. Anthracyclines

1. (anthracyclin\$ or anthracyclines).mp. or exp Anthracycline/

2. anthracycline antibiotics.mp. or exp Anthracycline Antibiotic Agent/

3. exp Anthracycline Derivative/

4. (4-demethoxydaunorubicin or 4 demethoxydaunorubicin or 4-desmethoxydaunorubicin or 4 desmethoxydaunorubicin).mp. or exp idarubicin/

5. (IMI 30 or IMI30 OR IMI-30 or idarubicin hydrochloride).mp.

6. (NSC 256439 or NSC-256439 or NSC256349 or idarubicin or idarubic\$).mp.

7. (4'-epiadriamycin or 4' epiadriamycin or 4'-epidoxorubicin or 4' epidoxorubicin or 4'-epi-doxorubicin or 4' epi doxorubicin).mp.

8. (4'-epi-adriamycin or 4' epi adriamycin or 4'-epi-DXR or 4' epi DXR).mp.

9. exp epirubicin/ or (epirubicin or epirubicin hydrochloride or epirubic $\$$ or farmorubicin).mp.

10. (IMI-28 or IMI 28 or IMI28 or NSC 256942 or NSC-256942 or NSC256942).mp.

11. (adriablastine or adriblastin or adriablastin or adriamycin).mp.

12. (DOX-SL or DOX SL or doxorubicin hydrochloride or doxorubic $\$$ or adramyc\$).mp.

13. (dauno-rubidomycine or dauno rubidomycin or rubidomycin or rubomycin or daunomycin).mp.

14. (cerubidine or daunoblastin or daunoblastine or daunorubicin hydrochloride or daunorubic\$).mp.

15. (NSC-82151 or NSC 82151 or NSC82151).mp.

16. (daunoxome or daunoxom $\$$ or daunosom $\$$ or doxil or caelyx or liposomal doxorubicin or myocet or doxorubicin or daunorubicin).mp.

17. $\exp$ DAUNORUBICIN DERIVATIVE/ or exp DAUNORUBICIN/ or exp IDARUBICIN DERIVATIVE/ or exp IDARUBICIN/ or exp DOXORUBICIN DERIVATIVE/ or exp DOXORUBICIN/ or exp EPIRUBICIN/

18. or/1-17

3. Childhood cancer

1. (leukemia or leukemi\$ or leukaemi\$ or (childhood adj ALL) or acute lymphocytic leukemia).mp.

2. (AML or lymphoma or lymphom\$ or hodgkin or hodgkin\$ or T-cell or B-cell or non-hodgkin).mp.

3. (sarcoma or sarcom $\$$ or Ewing $\$$ or osteosarcoma or osteosarcom $\$$ or wilms tumor or wilms $\$$ ). $m p$.

4. (nephroblastom $\$$ or neuroblastoma or neuroblastom $\$$ or rhabdomyosarcoma or rhabdomyosarcom $\$$ or teratoma or teratom $\$$ or hepatoma or hepatom \$ or hepatoblastoma or hepatoblastom\$).mp.

5. (PNET or medulloblastoma or medulloblastom\$ or PNET\$ or neuroectodermal tumors or primitive neuroectodermal tumor\$ or retinoblastoma or retinoblastom $\$$ or meningioma or meningiom $\$$ or glioma or gliom $\$$ ).mp.

6. (pediatric oncology or paediatric oncology).mp.

7. ((childhood adj cancer) or (childhood adj tumor) or (childhood adj tumors) or childhood malignancy or (childhood adj malignancies) or childhood neoplasm\$).mp.

8. ((pediatric adj malignancy) or (pediatric adj malignancies) or (paediatric adj malignancy) or (paediatric adj malignancies)).mp.

9. ((brain adj tumor\$) or (brain adj tumour\$) or (brain adj neoplasms) or (brain adj cancer\$) or brain neoplasm\$).mp.

10. (central nervous system tumor\$ or central nervous system neoplasm or central nervous system neoplasms or central nervous system tumour\$).mp.

Medical interventions for treating anthracycline-induced symptomatic and asymptomatic cardiotoxicity during and after treatment for 
11. intracranial neoplasm $\$ . \mathrm{mp}$.

12. LEUKEMIA/ or LYMPHOMA/ or brain tumor/ or central nervous system tumor/ or teratoma/ or sarcoma/ or osteosarcoma/

13. nephroblastoma/ or neuroblastoma/ or rhabdomyosarcoma/ or hepatoblastoma/ or medulloblastoma/ or neuroectodermal tumor/ or retinoblastoma/ or meningioma/ or glioma/ or childhood cancer/

14. or/1-13

\section{RCTs, CCTs}

1. Randomized Controlled Trial/

2. Controlled Clinical Trial/

3. randomized.ti,ab.

4. placebo.ti,ab.

5. randomly.ti,ab.

6. trial.ti,ab.

7. groups.ti,ab.

8. drug therapy.sh.

9. or/1-8

10. Human/

11.9 and 10

The final combined search was:

\section{1 AND 2 AND 3 AND 4}

$[\mathrm{mp}=$ title, abstract, subject headings, heading word, drug trade name, original title, device manufacturer, drug manufacturer name; sh = subject heading; ti,ab = title, abstract; / = Emtree term; $\$=$ zero or more characters $;$ RCT = randomized controlled trial; CCT = controlled clinical trial]

\section{Appendix 4. Search strategy for trial registers}

(anthracycline or daunorubicin or doxorubicin or adriamycin or idarubicin or epirubicin or farmorubicin or daunoxome or liposomal doxorubicin) and (heart failure or heart toxicity or cardiac toxicity or cardiotoxicity)

\section{Appendix 5. Search strategy for conference proceedings}

(anthracycline or daunorubicin or doxorubicin or adriamycin or idarubicin or epirubicin or farmorubicin or daunoxome or liposomal doxorubicin) and (heart failure or heart toxicity or cardiac toxicity or cardiotoxicity) and (child or pediatric) and trial

\section{WHAT'S NEW}

Last assessed as up-to-date: 25 September 2015.

\begin{tabular}{ll|l}
\hline Date & Event & Description \\
\hline 1 October 2015 & $\begin{array}{l}\text { New citation required but conclusions have not } \\
\text { changed }\end{array}$ & $\begin{array}{l}\text { Unfortunately, we could include no new studies in the } \\
\text { review. As a result the conclusions have not changed }\end{array}$ \\
\hline 25 September 2015 & New search has been performed & $\begin{array}{l}\text { The search for eligible studies was updated to 25 } \\
\text { September 2015 }\end{array}$ \\
\hline
\end{tabular}

Medical interventions for treating anthracycline-induced symptomatic and asymptomatic cardiotoxicity during and after treatment for 


\section{CONTRIBUTIONSOFAUTHORS}

Daniel Cheuk performed the updated search, contributed to the interpretation of the results, and wrote and revised the manuscript.

Elske Sieswerda performed the updated search, contributed to the interpretation of the results, and critically reviewed the updated review.

Elvira van Dalen contributed to the interpretation of the results and reviewed the updated review.

Aleida Postma contributed to the interpretation of the results and critically reviewed the updated review.

Leontien Kremer contributed to the interpretation of the results and critically reviewed the updated review.

\section{DECLARATIONSOF INTEREST}

Daniel Cheuk: None known.

Elske Sieswerda: None known.

Elvira van Dalen: None known.

Aleida Postma: None known.

Leontien Kremer: None known.

\section{SOURCES OF SUPPORT}

\section{Internal sources}

- No sources of support supplied

\section{External sources}

- Stichting Kinderen Kankervrij (KiKa), Netherlands.

\section{DIFFERENCES BETWEEN PROTOCOLANDREVIEW}

As opposed to the protocol, which stated that we would use the criteria and definitions in the module of Cochrane Childhood Cancer (as available in 2008: Module CCG), we based the 'Risk of bias' assessment on both the earlier mentioned module and on information provided in the Cochrane Handbook for Systematic Reviews of Interventions (Higgins 2008). We added new items (that is generation of allocation sequence, selective outcome reporting, and other sources of bias) and adjusted some definitions.

Based on a peer reviewer's comment, we added to the methods section the Fisher's exact test, P for situations in which only one study was available and there were no events in one of the treatment groups.

One review author performed the data extraction and 'Risk of bias' assessment of included studies, which another review author checked.

We did not contact authors in order to obtain missing data during the data extraction and 'Risk of bias' assessment.

Medical interventions for treating anthracycline-induced symptomatic and asymptomatic cardiotoxicity during and after treatment for 


\section{INDEX TERMS}

\section{Medical Subject Headings (MeSH)}

Adult Survivors of Child Adverse Events; Angiotensin-Converting Enzyme Inhibitors [adverse effects; *therapeutic use]; Anthracyclines [*administration \& dosage; adverse effects]; Antibiotics, Antineoplastic [*adverse effects]; Cardiotonic Agents [*therapeutic use]; Enalapril [adverse effects; * therapeutic use]; Heart Failure [chemically induced; *drug therapy; mortality]; Neoplasms [drug therapy]; Phosphocreatine [* therapeutic use]; Randomized Controlled Trials as Topic

\section{MeSH check words}

Adult; Child; Humans 